ISSN 2072-4292

www.mdpi.com/journal/remotesensing

Article

\title{
Monitoring Soil Salinization in Keriya River Basin, Northwestern China Using Passive Reflective and Active Microwave Remote Sensing Data
}

Ilyas Nurmemet ${ }^{1,2}$, Abduwasit Ghulam 1,3, Tashpolat Tiyip ${ }^{1, *}$, Racha Elkadiri ${ }^{2}$, Jian-Li Ding ${ }^{1}$, Matthew Maimaitiyiming ${ }^{3}$, Abdulla Abliz ${ }^{1,4}$, Mamat Sawut ${ }^{1}$, Fei Zhang ${ }^{1}$, Abdugheni Abliz ${ }^{1}$ and Qian Sun ${ }^{1}$

1 Ministry of Education Key Laboratory of Oasis Ecology and College of Resources and Environmental Sciences, Xinjiang University, Urumqi 830046, China;

E-Mails: ilyas777v@163.com (I.N.); dingj1@163.com (J.-L.D.); abdulla715@gmail.com (A.A.); korxat@xju.edu.cn (M.S.); zhangfei3s@163.com (F.Z.); abduhini0997@126.com (A.A.); sq061@163.com (Q.S.)

2 Department of Geosciences, Western Michigan University, Kalamazoo, MI 49008, USA; E-Mail: racha.elkadiri@wmich.edu

3 Center for Sustainability, Saint Louis University, St. Louis, MO 63108, USA; E-Mails: awulamu@slu.edu (A.G.); maimaitiyiming@slu.edu (M.M.)

4 Applied Physical Geography, Catholic University of Eichstätt-Ingolstadt, Eichstätt 85071, Germany

* Author to whom correspondence should be addressed; E-Mail: tash@xju.edu.cn; Tel.: +86-991-858-1102.

Academic Editors: Wolfgang Wagner and Prasad S. Thenkabail

Received: 13 April 2015 / Accepted: 6 July 2015 / Published: 13 July 2015

Abstract: Soil salinization is one of the most widespread soil degradation processes on Earth, especially in arid and semi-arid areas. The salinized soil in arid to semi-arid Xinjiang Uyghur Autonomous Region in China accounts for 31\% of the area of cultivated land, and thus it is pivotal for the sustainable agricultural development of the area to identify reliable and cost-effective methodologies to monitor the spatial and temporal variations in soil salinity. This objective was accomplished over the study area (Keriya River Basin, northwestern China) by adopting technologies that heavily rely on, and integrate information contained in, a readily available suite of remote sensing datasets. The following procedures were conducted: (1) a selective principle component analysis (S-PCA) fusion image was generated using Phased Array Type L-band SAR (PALSAR) backscattering coefficient $\left(\sigma^{\circ}\right)$ 
and Landsat Enhanced Thematic Mapper Plus (ETM+) multispectral image of Keriya River Basin; and (2) a support vector machines (SVM) classification method was employed to classify land cover types with a focus on mapping salinized soils; (3) a cross-validation method was adopted to identify the optimum classification parameters, and obtain an optimal SVM classification model; (4) Radarsat-2 (C band) and PALSAR polarimetric images were used to analyze polarimetric backscattering behaviors in relation to the variation in soil salinization; (5) a decision tree (DT) scheme for multi-source optical and polarimetric SAR data integration was proposed to improve the estimation and monitoring accuracies of soil salinization; and (6) detailed field observations and ground truthing were used for validation of the adopted methodology, and quantity and allocation disagreement measures were applied to assess classification outcome. Results showed that the fusion of passive reflective and active microwave remote sensing data provided an effective tool in detecting soil salinization. Overall accuracy of the adopted SVM classifier with optimal parameters for fused image of ETM+ and PALSAR data was $91.25 \%$ with a Kappa coefficient of 0.89 , which was further improved by the DT data integration and classification method yielding an accuracy of $93.01 \%$ with a Kappa coefficient of 0.92 and lower disagreement of quantity and allocation.

Keywords: soil salinization; Keriya River basin; image fusion; SVM classification; decision tree

\section{Introduction}

Soil salinization negatively affects crop growth and productivity, especially in arid and semi-arid areas where evaporation exceeds rainfall [1]. The global extent of primary salt-affected soils is $955 \mathrm{M}$ ha, while secondary salinization affects some $77 \mathrm{M}$ ha, with $58 \%$ of these are situated in irrigated areas [2]. Twenty percent of all irrigated land is salt-affected [2], and this proportion increases as a consequence of human activities and increasing population pressure particularly in countries like China where overpopulation poses a significant threat to the eco-environment[1,3]. Thus, it is imperative to detect, monitor, and map soil salinity over space and time to prevent further land degradation, and to ensure the sustainable development of agriculture [4,5].

Salt-affected soils can be discriminated using the visible and infrared portions of remote sensing spectra [2,6-9]. A growing body of studies, aided by statistical analyses of field spectroscopy data and satellite remote sensing observations demonstrates that both multispectral [10-15] and hyperspectral passive reflectance data can be used to map soil salinization at landscape scales [16]. However, passive optical remote sensing based approaches may be hampered over coastal areas, black-clay soils, and desert areas, due to the smoothness and the white color of the formed crust [2]. In the microwave wavelengths, the signal is sensitive to the dielectric properties of the target [17]. Studies indicate that the change of soil moisture and salinity affects soil conductivity which influences soil dielectric constant $[18,19]$. Radar data have the potential for evaluating soil salinity through monitoring and mapping salt-affected areas [20]. 
Image fusion of multi-sensor remote sensing data does not only allow filling the gaps in datasets, but also provides a unique combination of spectral and textural signatures for target detection [21,22]. For example, backscattering coefficient $\left(\sigma^{\circ}\right)$ from synthetic aperture radar (SAR) data provides detailed information of surface roughness and moisture content, while passive visible and infrared spectra provide measurements of vegetation types, plant responses to soil conditions and/or direct measurements of soil salinity. Therefore, the fusion of passive reflective and active microwave remote sensing images utilizes the advantages of both datasets.

The main objective of this contribution is to monitor soil salinization in Keriya River Basin, Northwestern China by using the fusion of datasets from active synthetic aperture radar (SAR) and passive reflective imagery in the optical domain.

\section{Study Site}

Northwestern China, particularly Xinjiang Uyghur Autonomous Region (XJUAR), is one of the most critical areas for agricultural and cotton production. The total area of salt-affected cultivated land in Xinjiang is about $1.47 \mathrm{M}$ ha, which accounts for $31.1 \%$ of the total cultivated land which suffered from wide spread salinized soil [23,24]. The Keriya River Basin is a typical arid land located at the northern foot of Kunlun Mountains along the southern edge of the Taklimakan Desert in XJUAR (Figure1).

The region has a warm continental arid climate with an average temperature of $11.6{ }^{\circ} \mathrm{C}$, with a minimum average temperature of $-5.8{ }^{\circ} \mathrm{C}$ in January, and maximum average temperature of $25{ }^{\circ} \mathrm{C}$ in July. The total annual radiation is $6.117 \times 10^{5} \mathrm{~J} / \mathrm{cm}^{2}$ and the annual sunshine duration is $2.7346 \times 10^{3} \mathrm{~h}$. Multi-year average evaporation is $2498 \mathrm{~mm}$; the average annual precipitation is $44.7 \mathrm{~mm}$; the evaporation rainfall ratio is approximately $54: 1$, and the frost-free period is approximately 200 days.

The Keriya River is a seasonal river which originates from the Kunlun piedmont. It flows through the Keriya Oasis which entirely depends on the water resources from the Keriya River, and vanishes in the sand dunes of the Taklimakan desert [25]. Since the 1950s, the Keriya River basin has been intensely exploited. The area is suffering from severe water shortages due to excessive pressure from population increase, agricultural expansion, and most importantly, from the steady encroachment of salinization and desertification [26]. The vegetation varies depending on water availability, and includes spare brush vegetation and halophilic plants [27]. The main soil types in the area are the meadow soil and the brown desert soil which are characterized by fine grains, low permeability, high water table and high mineralization. The highly salt-affected soil of Keriya River basin hampers the local agricultural productivity. Salt concentration in the soil has a strong impact on crop yields and agricultural production due to poor land and water management and the expansion of the agricultural frontier into marginal ecotones in the Keriya River Basin. The improvement of salt-affected soils is the key to achieve sustainable food production in the region, which requires the monitoring and mapping of soil salinization at an early stage for an effective soil reclamation program. 

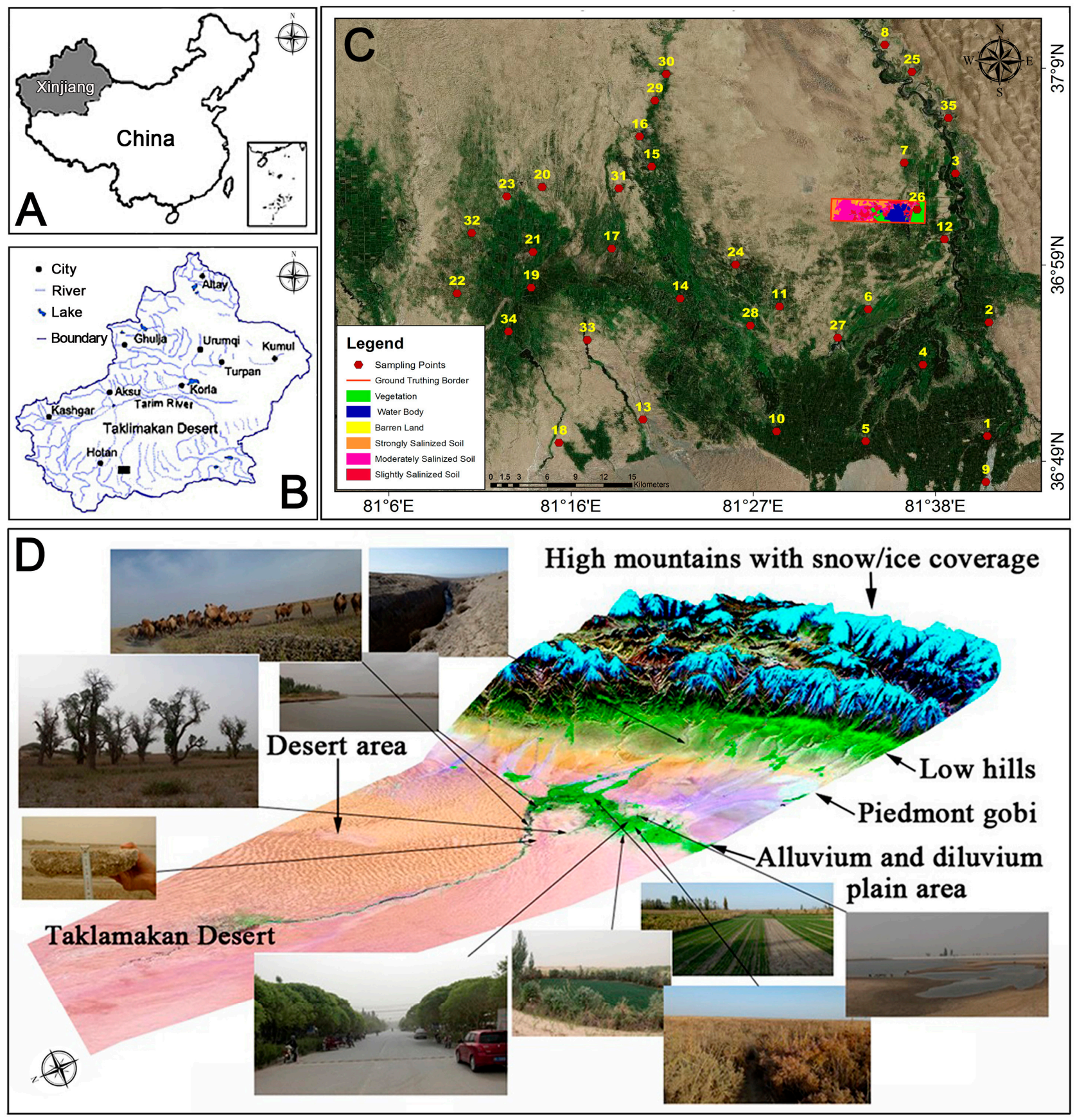

Figure 1. Location map of the study area showing overview map of China and the Xinjiang Uyghur Autonomous Region (XJUAR) (A and B), topographic map of the map sampling points of study area $(\mathbf{C})$ and the Keriya River Basin (D). The red solid circles represent field sampling locations. The red rectangular line is the location of ground truthing. The basin is located in the southern part of XJUAR, situated to the north of Kunlun Mountain and the southern edge of the Taklimakan Desert. 


\section{Data}

\subsection{Field Data}

Six field campaigns were conducted between 2011 and 2013 mainly during dry seasons (from May to October). Thirty five field investigation sites were selected for soil sampling (Figure 1C), which covers a range of land covers and soil characteristics. At every site of a regular grid of $20 \mathrm{~m} \times 20 \mathrm{~m}$ plots, five samples were taken from the topsoil $(0 \sim 20 \mathrm{~cm})$. In total, 175 samples were collected to measure soil salinity and soil moisture for laboratory analysis. The first two campaigns (August 2011 and June 2012 respectively) focused on collecting ground reference data (GRD) for training samples and different land cover and land use (LCLU) classes where the field samples were collected. During these field trips, the weather was dry with low to no precipitation. Therefore, the soil moisture and salinity profile in the soil was consistent so that the different types of soil salinity are representative of the area typical conditions. The GRD were recorded for the patches of salinized soils, along with their environmental contexts, e.g., co-existing vegetation, LCLU, vegetation type, fraction of vegetation, and average vegetation height in each spot (Table 1). A total of 195 sample plots were collected as training sample plots for image classification. Figure 2 shows salinized soil, land-cover and vegetation types.

Three field campaigns were conducted from 2012 to 2013 mainly during the dry season from August to October for further investigation and validation. A total of 180 patches (30 plots for each type of salinized soil and 90 plots for other land cover types) were set up for validation and accuracy assessment of the classification results, which were distributed evenly across the study area.

The soil samples were air-dried and sieved through two $\mathrm{mm}$ sieves, and soil salt concentration (i.e., total soluble salt) was measured in a laboratory by following steps. The soil samples were mixed with distilled water and marinated and quivered so that the soil samples were fully dissolved to measure total soluble salt. Electrical conductivity (EC) was determined in soil liquid solution using conductivity meter (inoLab ${ }^{\circledR}$ Cond 7310, WTW) with the soil and water dilution ratio of 1:5. In this step we measured EC of 1:5 soil-water extract in $\mathrm{mS} / \mathrm{cm}$. Finally the total soluble salt content (in $\mathrm{g} / \mathrm{Kg}$ ) was calculated by means of regression equation established between EC and total soluble salt.

Table 1. LCLU classes with varying severity of soil salinization in the Keriya River Basin.

\begin{tabular}{ccl}
\hline Abbreviation & Class & \multicolumn{1}{c}{ Characteristics } \\
\hline HS & $\begin{array}{c}\text { Strongly } \\
\text { Salinized soil }\end{array}$ & $\begin{array}{l}\text { almost barren land with vegetation coverage less than } 5 \% \text {, with salt crust } \\
\text { of } 2 \sim 7 \mathrm{~cm} \text {, top soil soluble salt } \geqslant 20 \mathrm{~g} \cdot \mathrm{kg}^{-1}, \text { water table depth is } 0.5 \sim 1.5 \mathrm{~m}\end{array}$ \\
\hline MS & $\begin{array}{c}\text { Moderately } \\
\text { Salinized soil }\end{array}$ & $\begin{array}{l}\text { main vegetation types are Tamarix chinensis Lour, Halocnemum } \\
\text { strobilaceum, Halostachys caspica, Phragmites communis, Alhagi } \\
\text { pseudalhagi with vegetation coverage of around } 5 \% \sim 15 \% \text {, with salt crust of } \\
1 \sim 4 \mathrm{~cm} \text {, top soil soluble salt is about } 10 \sim 20 \mathrm{~g} \cdot \mathrm{kg}^{-1}, \text { water table depth is } 1 \sim 2 \mathrm{~m}\end{array}$ \\
\hline & main vegetation types are Tamarix chinensis Lour, Phragmites communis, \\
SS & Slightly & $\begin{array}{l}\text { Haloxylon ammodendron, Karelinia caspica, Alhagi pseudalhagi with } \\
\text { vegetation coverage of around } 30 \%, \text { with thin salt crust (around } 0 \sim 2 \mathrm{~cm}), \\
\text { top soil soluble salt is about } 5 \sim 10 \mathrm{~g} \cdot \mathrm{kg}^{-1}, \text { water table depth is } 1.4 \sim 3 \mathrm{~m}\end{array}$ \\
\hline WB & Walinized soil Body & river, lake, reservoir, pond and swamp \\
\hline VG & Vegetation & grassland, cropland, Euphrates Poplar forests, dense shrubland \\
\hline BL & Barren land & gobi, desert \\
\hline
\end{tabular}



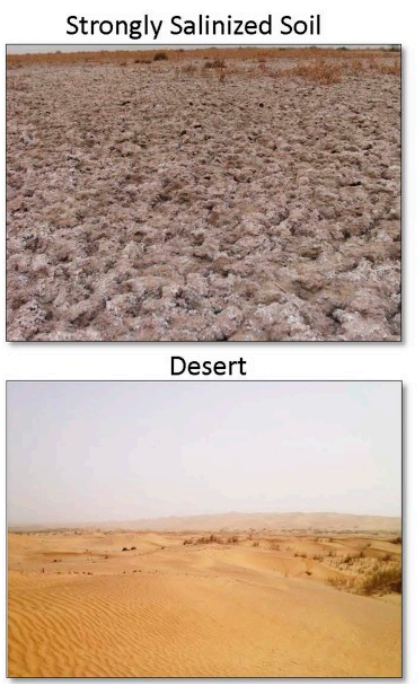

Grassland

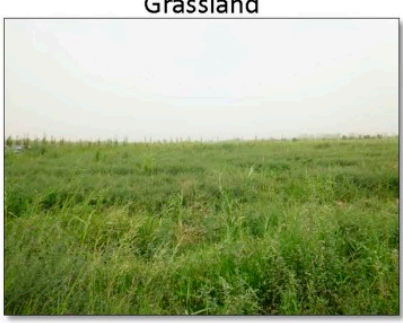

Alhagi sparsifolia

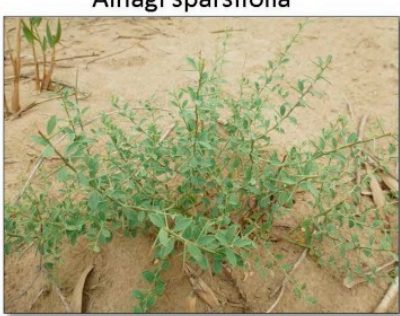

Strongly Salinized Soil

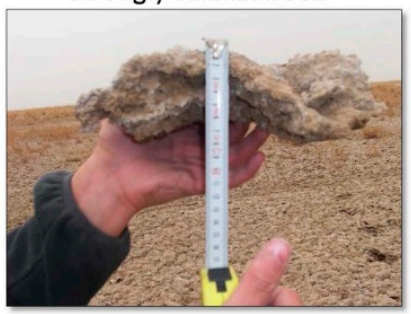

Keriya River

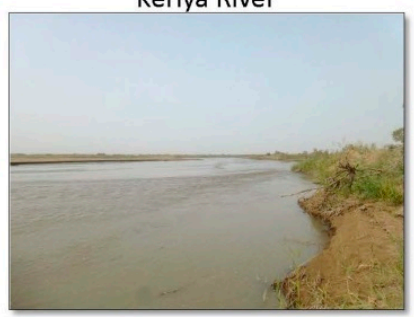

Cropland

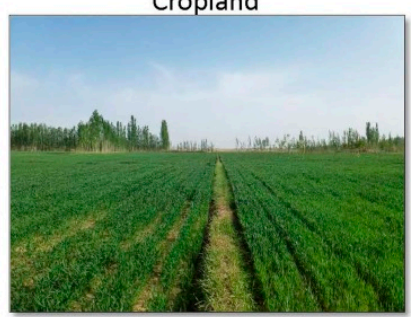

Tamarix chinensis Lour

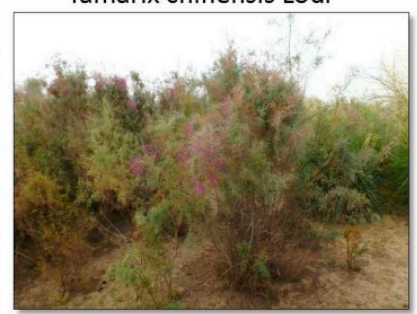

Moderately Salinized Soil

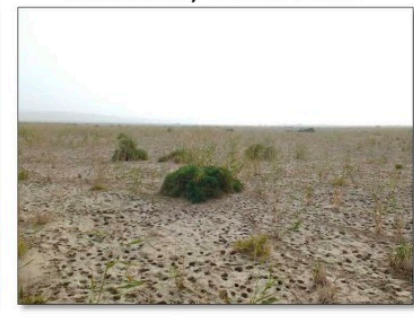

Swamp

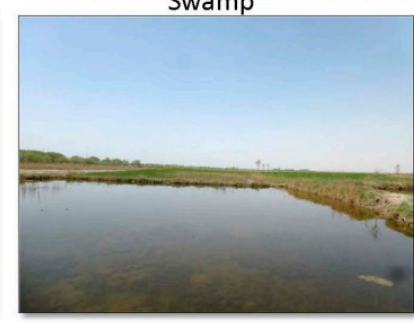

Populus euphratica

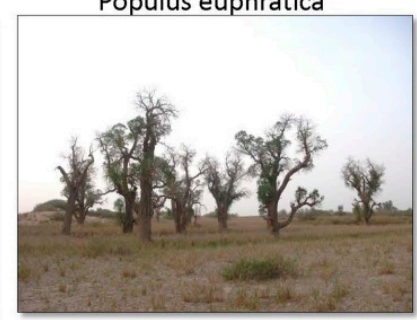

Karelinia caspica

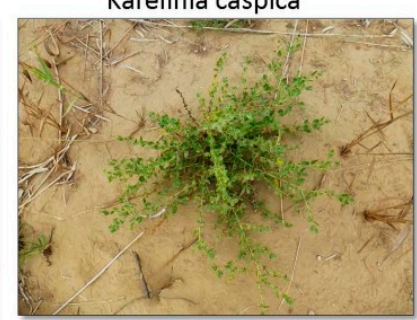

Slightly Salinized Soil

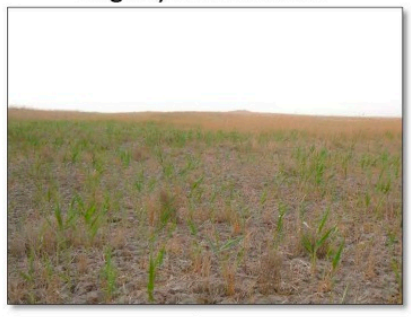

Lake

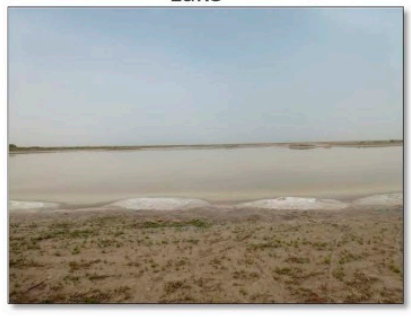

Phragmites communis

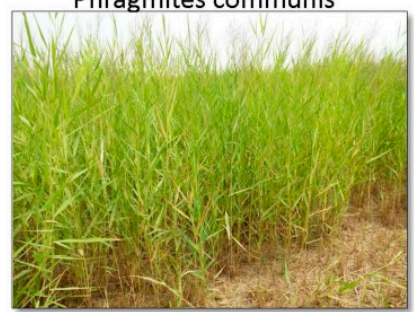

Halocnemum strobilaceum

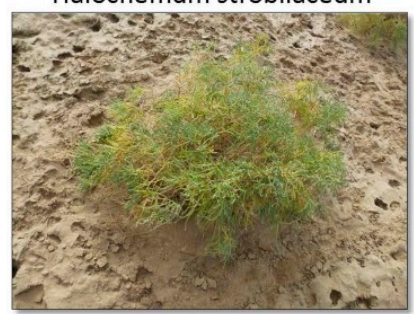

Figure 2. Land-cover classes, different salinized soil types and major salt tolerant vegetation types in the Keriya River basin.

The last field trip conducted in August, 2013 was prioritized for defining the degree of salinization and corresponding land cover types. The ground truthing (Figure 1C) covers $2 \times 8 \mathrm{~km}^{2}$ area, 40 sampling plots in $500 \mathrm{~m}$ grid cell distributed mainly in the salinized area were collected and categorized as strongly, moderately and slightly salinized soil according to top soil salt concentration along with other traits such as vegetation coverage and type, water table and soil moisture. Figure 2 shows the different degrees of salinization as observed in the field as well the various land use types in the study area.

\subsection{Remote Sensing Data}

A Landsat Enhanced Thematic Mapper Plus (ETM+) image collected on 5 August 2011, covering the Keriya River basin was obtained from USGS EROS Data Center. Gap filling was performed for the ETM+ image to correct the missing strips due to the failure of the Scan Line Corrector (SLC). A single image local linear histogram matching, which employs a triangulation technique in a moving window of each missing pixel, was used to fill the gaps in the SLC-Off data following Scaramuzza et al. [28]. Subsequently, the ETM+ image covering the study area was combined into one single gap-filled image. Our choice for this method was based on the fact that it is simple, easy to implement, and very effective 
for cloud-free, high quality images. Phased Array type L-band Synthetic Aperture Radar (PALSAR) data were collected over the study area on 17 July 2010. The PALSAR data used in this work was acquired in fine-beam dual-polarization (FBD) mode (HH and HV), in an ascending orbit and with the default off-nadir angle of $34.3^{\circ}$ and an incident angle of $38.77^{\circ}$. Pixel spacing in slant range and azimuth directions was $9.37 \mathrm{~m}$ and $3.16 \mathrm{~m}$, respectively, which gave a nominal ground resolution of $18.5 \mathrm{~m}$ when processed with one number of looks for both range and azimuth.

We also used Dual-polarization (HH+HV) Radarsat-2 image acquired on 13 September 2008 by MacDonald, Dettwiler and Associates Ltd. (MDA). The data were processed at level 1 and provided in SAR Georeferenced Fine format (SGF) which was generated by standard ground coordinate pixel dimensions. The data were acquired in a wide swath beam double polarization mode at an ascending orbit with a $30.89^{\circ}$ incidence angle. Nominal spatial resolutions were $19.2 \sim 40.0 \mathrm{~m}$ and $24.7 \mathrm{~m}$ in range and azimuth directions, respectively.

SAR datasets in a single look complex were processed using SARscape modules of ENVI ${ }^{\circledR}$ image processing and analysis software, from EXELIS Visual Information Solutions. Processing steps include: (1) focusing; (2) orbital correction; (3) multi looking (looks in range and azimuth, respectively); (4) speckle filtering using an adaptive Lee filter [29]; (5) radiometric calibration [30,31], using a Shuttle Radar Topography Mission (SRTM) digital elevation model (DEM) and radiometric normalization (i.e., modified cosine model) [32]; (6) geocoding; and (7) image resizing for optimal resolution of $20 \mathrm{~m} \times 20 \mathrm{~m}$ for data fusion. Preprocessing generated an orthorectified, geocoded and radiometrically calibrated backscattering coefficient image in $\mathrm{dB}$ (Figure 3B,C).
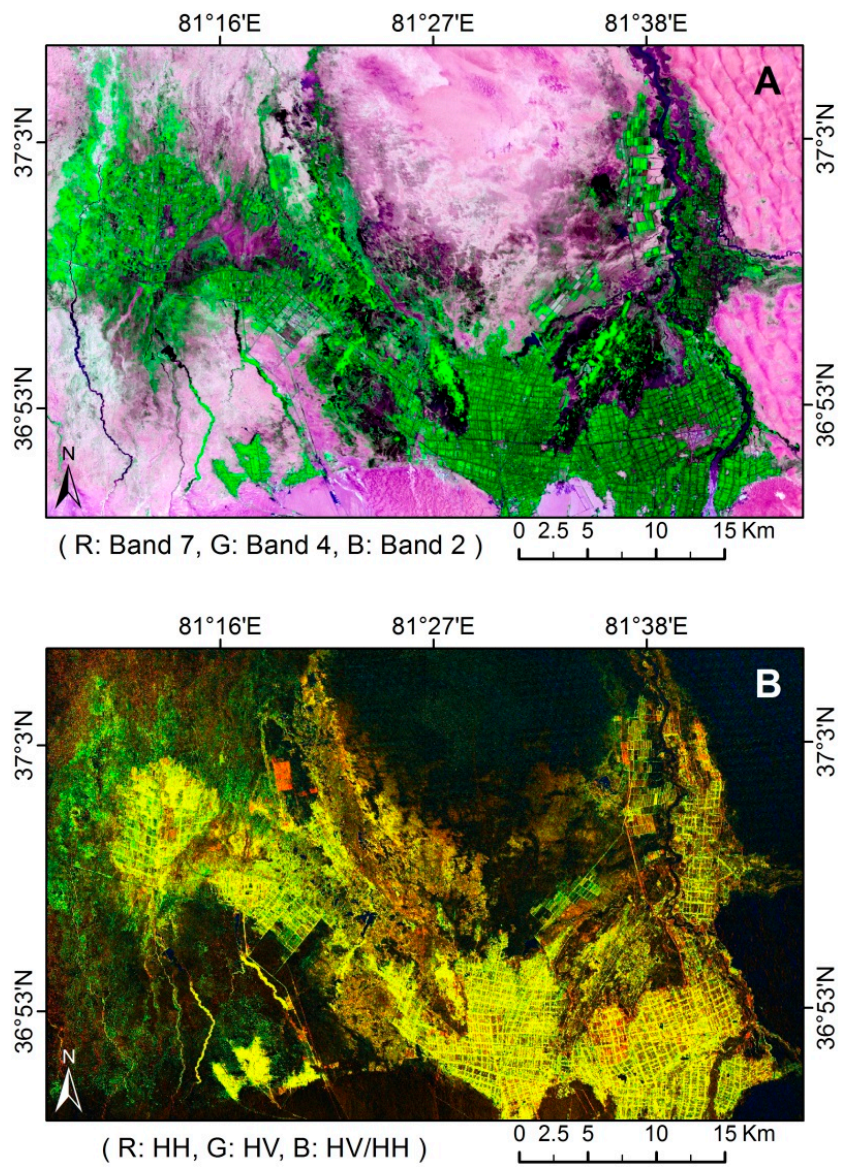

Figure 3. Cont. 


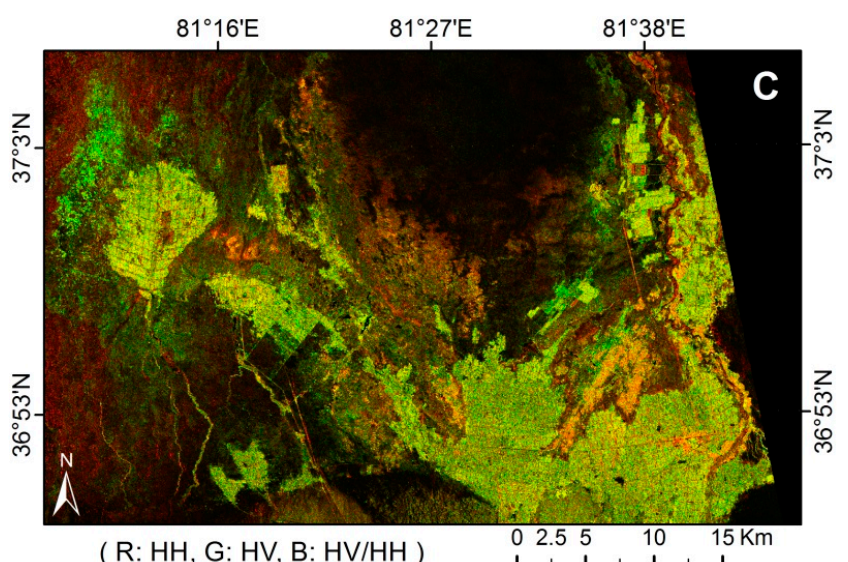

Figure 3. The pre-processed ETM+ (A); PALSAR (B) and Radarsat-2 (C) images.

The digital datasets including satellite imagery and field GPS collections, were geo-referenced to the Universal Transverse Mercator (UTM) coordinate system, Zone 44 North with World Geodetic System Datum of 1984 (WGS84).

\section{Methods}

Figure 4 shows the workflow of the study, which is detailed in the following sections.

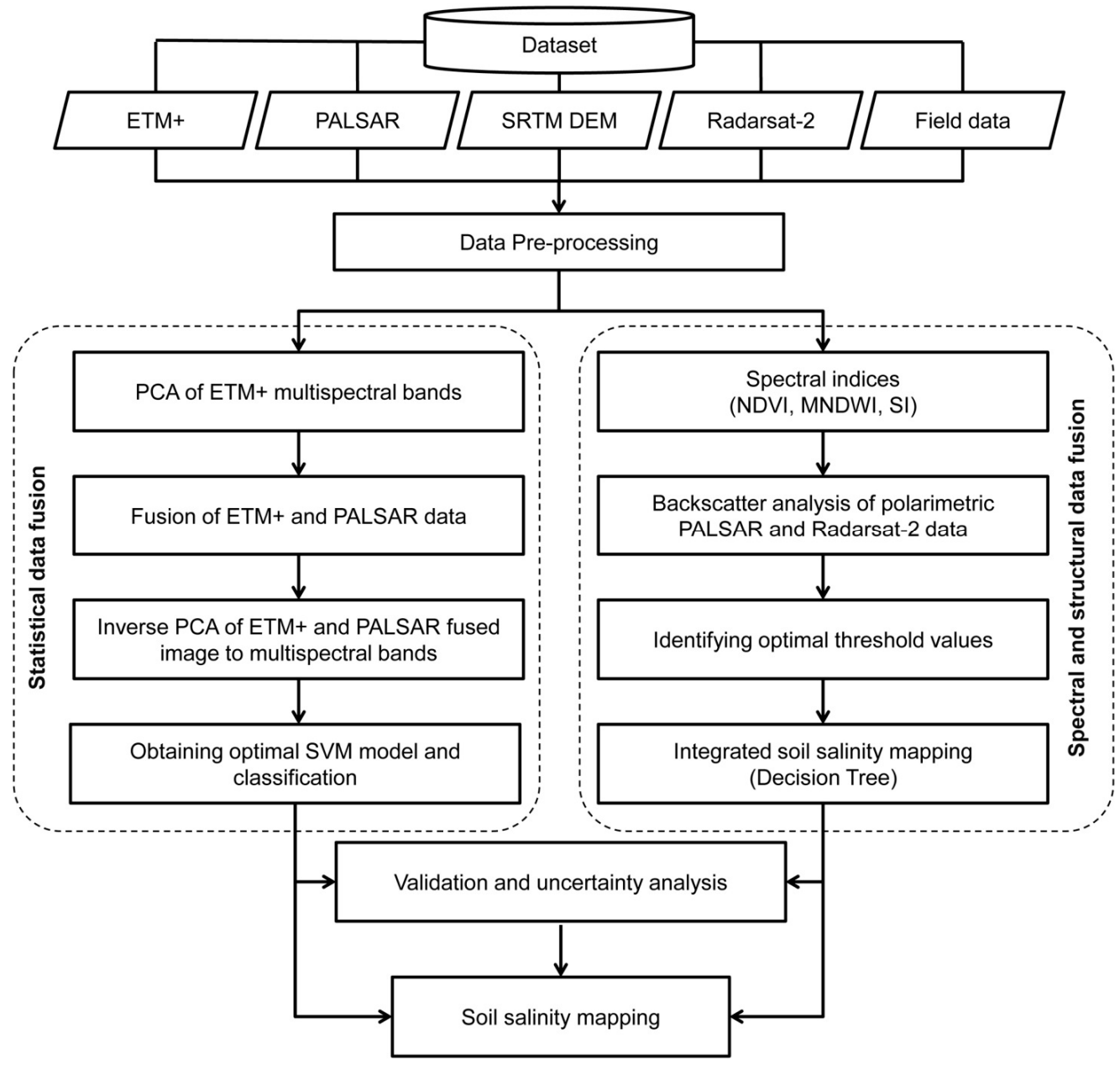

Figure 4. Overall workflow of the study. 


\subsection{Spectral Indices}

Landsat ETM+ data were radiometrically corrected following Chander et al. [33]; then the top-of-atmosphere reflectance was converted to surface reflectance value using 6S code [34] (Figure 3A).

Three spectral indices were extracted using ETM+ datasets:

1. Normalized difference vegetation index (NDVI). In the Keriya River basin, NDVI value of most vegetation types (grassland, cropland, forests and shrubland) is greater than 0.28 , while the other non-vegetated land cover types were less than 0.3 . Therefore, the vegetated and non-vegetated land cover types could be distinguished using NDVI threshold.

2. Modified normalized difference water index (MNDWI) [35]. The MNDWI was modified after the NDWI as follows:

$$
\text { MNDWI }=(\text { Green }- \text { MIR }) /(\text { Green }+ \text { MIR })
$$

where "Green" stands for a green band and "MIR" stands for a middle infrared band in the Landsat ETM+ images, representing ETM+ band 2 and band 5, respectively. The analysis on the study area showed that the MNDWI index could accurately separate water bodies from other land-cover types.

3. Salinity Index (SI). Reflectance data of Landsat ETM+ band 1 (B1) and band 3 (B3) could be applied to calculate the Salinity Index [36-39] as follows:

$$
\text { Salinity index } S I=\sqrt{B 1 \times B 3}
$$

The SI was utilized in this study because: (1) the identification of the spectral response model of saline soils is effective in the separation of saline soil types [7]; and (2) the red waveband (620 680 nm) of ETM+ image is sensitive to soil salinity [9]. Studies [7,40] found that the blue and red wavebands of Landsat data performed high spectral reflectance for salt-affected soils at low moisture content.

\subsection{Coregistration of Passive Reflective and Active Microwave Data}

For a proper integration of the optical and radar data for accurate soil information extraction, the precise coregistration of Landsat, PALSAR and Radarsat-2 datasets is necessary. The coregistration accuracy between these datasets was calculated using a gradient cross-correlation technique [41] which offers a sub-pixel coregistration assessment by detecting and matching features in both images over a window containing various pixels. To evaluate the coregistration accuracy between the PALSAR, Radarsat-2 and ETM+ data, a total of uniformly distributed 85 image features were selected inside and outside of the Keriya River Oasis. The average offset between these features was 0.77 pixels with $92 \%$ of the shifts smaller than 1.5 pixels (at $20 \mathrm{~m}$ pixel size).

\subsection{Data Fusion}

Multi-sensor data fusion is useful because it takes advantage of different spectral and/or spatial information for effective image interpretation [42]. HH and HV polarized L band PALSAR images and $\mathrm{ETM}+$ six band images were used for image fusion. We implemented selective principle component analysis (S-PCA) transformation, rather than the conventional standard PCA method, which fully exploits the spectral characteristics of optical data and the textural and spatial traits of both $\mathrm{HH}$ and $\mathrm{HV}$ 
polarization of PALSAR data. The specific procedures include: (1) principal component (PC) forward transformation was performed on the multi-spectral ETM+ data and six uncorrelated output PC bands were produced; (2) PALSAR HH and HV backscattering data were scaled from 16 bit to 8 bit in order to match the values of PCs of optical data and to minimize distortion of the spectral information; consequently, 5th and 6th PCs which usually contain sparse variance, were substituted with the scaled $\mathrm{HH}$ and HV bands of PALSAR data; and (3) an inverse transformation was conducted.

\subsection{Support Vector Machine (SVM) Classification}

The SVM method is a non-parametric approach based on the statistical learning theory [43]. For a given training sample belonging to two different classes, SVM derives a hyperplane that is at a maximum distance from the closest points belonging to both classes. In the case of a two-class pattern recognition problem in which the classes are linearly separable, the SVM selects the one that minimizes the generalization error from among the infinite number of linear decision boundaries. Thus, the selected decision boundary will be the one that leaves the greatest margin between the two classes, where a margin is defined as the sum of the distances to the hyperplane from the closest points of the two classes [43].

Typically, a multi-class SVM is implemented by combining several two-class SVMs. Here, we used the "one-against-one" (OAO) approach and the Gaussian radial basis function (RBF) kernel for multi-class. Utilizing RBF kernel for SVM and obtaining optimal SVM classification model is of utmost importance to achieve the best set of penalty parameter $C$ and kernel parameters $\gamma$ for specific training datasets. In this case, we adopted the cross-validation search strategy [44], which employs a multiclass SVM OAO method [45]. The predicted set of optimal penalty parameter $C$ and kernel parameters $\gamma$ achieved with highest CV accuracy was used to classify different land cover types and salinized soils. Final results were sieved and clumped to eliminate spurious pixels from the classification results.

\subsection{Decision Tree}

Decision tree (DT) classifier is a simple and widely used classification technique. DT classifier is an effective method to incorporate data of a variety of types and from multiple sources to find pixels that fulfill the criteria [21]. Decision trees are made up of a series of binary criteria that are used to determine the correct category for each pixel. The decisions are based on any available characteristic of the dataset or decision rules derived from any other statistical software packages. DT provides a robust and flexible approach when examining the effects of each input feature to determine each split in the final tree and select the most important input variables that achieve the best classification results. Studies indicate that decision tree classification is superior over traditional image classifiers [21,46-49].

The decision tree scheme is built on the basis of inputs from optical (ETM+), SVM classification result from S-PCA fusion image with best parameters, and SAR (PALSAR and Radarsat-2) images: (1) The root node consists of MNDWI and ETM+ band 4 (near infrared band) threshold values which extract water bodies including rivers, lakes, reservoirs, ponds, and swamps, from the set of input images; (2) Vegetation information was extracted using NDVI thresholds from the remaining land cover classes from root node, the environmental context of the vegetation in this step including croplands, grasslands and low density mixed Euphrates Poplar forests and shrublands; (3) In the second tree nodes, barren land is extracted directly from optimal SVM classification result of fused image, including desert and 
gobi; (4) In the third node, strongly salinized soil was extracted by using comprehensive threshold values from polarimetric PALSAR and Radarsat-2 images; (5) Finally, integrated threshold values were established through both optical reflective index of SI and microwave backscattering energy from polarimetric PALSAR and Radarsat-2 images, and slightly salinized soil was separated from moderately salinized soils.

\subsection{Accuracy Assessment}

The classification accuracy was assessed with confusion matrix, producer's and user's accuracies, overall accuracy, kappa coefficient, as well as quantity disagreement and allocation disagreement [50] based on ground truthing. The producer's and user's accuracies are measures of omission and commission errors [51]. The kappa coefficient is a measure of agreement that accounts for the rate of correct classification occurring by chance [52]. Quantity disagreement refers to the error in proportions between the ground references versus the classification, while allocation disagreement is the proportion of misplaced categories from the classified map with respect to spatial allocations in the reference data. It is more important to understand the disagreement than the agreement for practical purposes in terms of understanding a classifier performance [50,53]. Although the use of kappa coefficient is criticized [50] for its capability of accuracy assessment, the measure was provided as potential comparisons to previous studies. A set of 108 field sample plots (30 locations for each type of salt affected soil, and 90 plots for other land-cover types) were used as ground reference pixels.

\section{Results}

\subsection{Data Fusion}

Figure 5 shows the results of image S-PCA fusion, which demonstrates that both the spatial and spectral details are well represented and delineated. In addition, the S-PCA fusion image is similar to the ETM+ multispectral image with the PALSAR spatial resolution. It is worth noting that S-PCA outperformed a number of conventional data fusion techniques (figures are omitted).

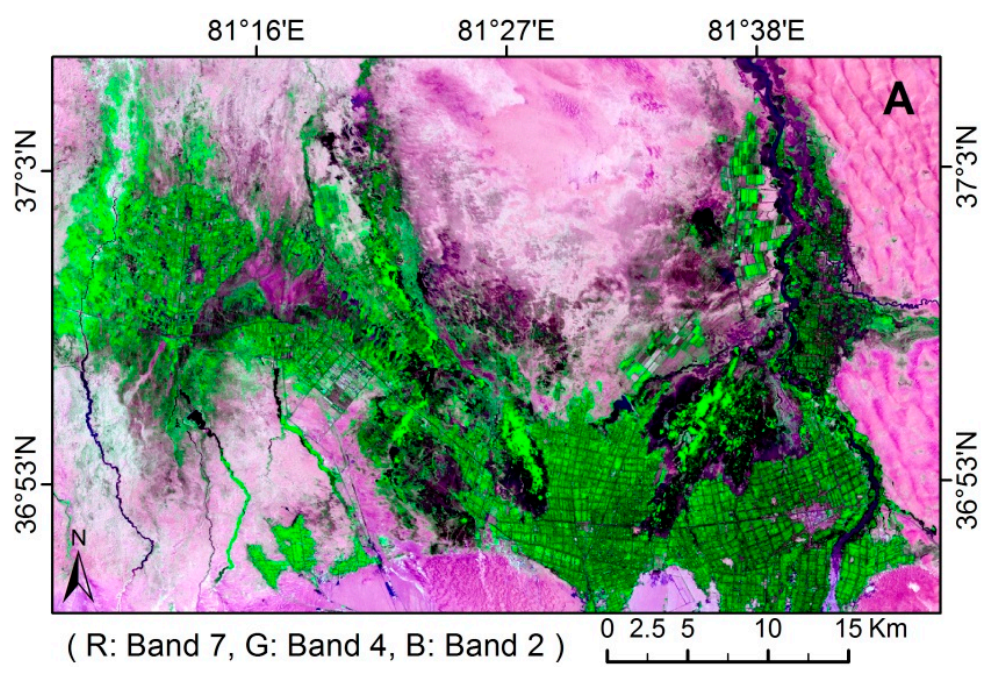

Figure 5. Cont. 


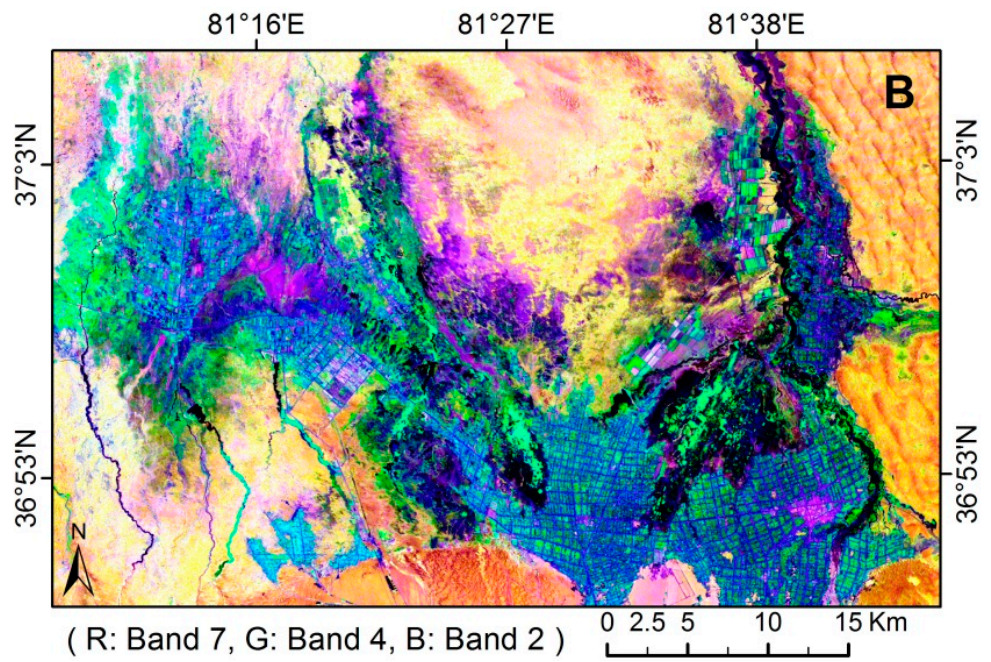

Figure 5. Comparison of ETM+ color composite (A) and S-PCA data fusion (B).

\subsection{SVM Classification and Accuracy}

\subsubsection{Optimal SVM Parameters}

A cross-validation (CV) search was conducted for the training data of both ETM+ and S-PCA fusion images to determine the best penalty parameter $C$ and kernel parameters $\gamma$. The $C V$ search results are represented in two dimensions (2D) and three dimensions (3D) in Figure 6. The optimal SVM classification model was obtained with parameters $C=512$ and $\gamma=1024$, and with a CV accuracy of 99.24\% for the ETM+ image, and with parameters $C=11.31$ and $\gamma=90.51$ and CV accuracy of 98.66\% for the fused image.
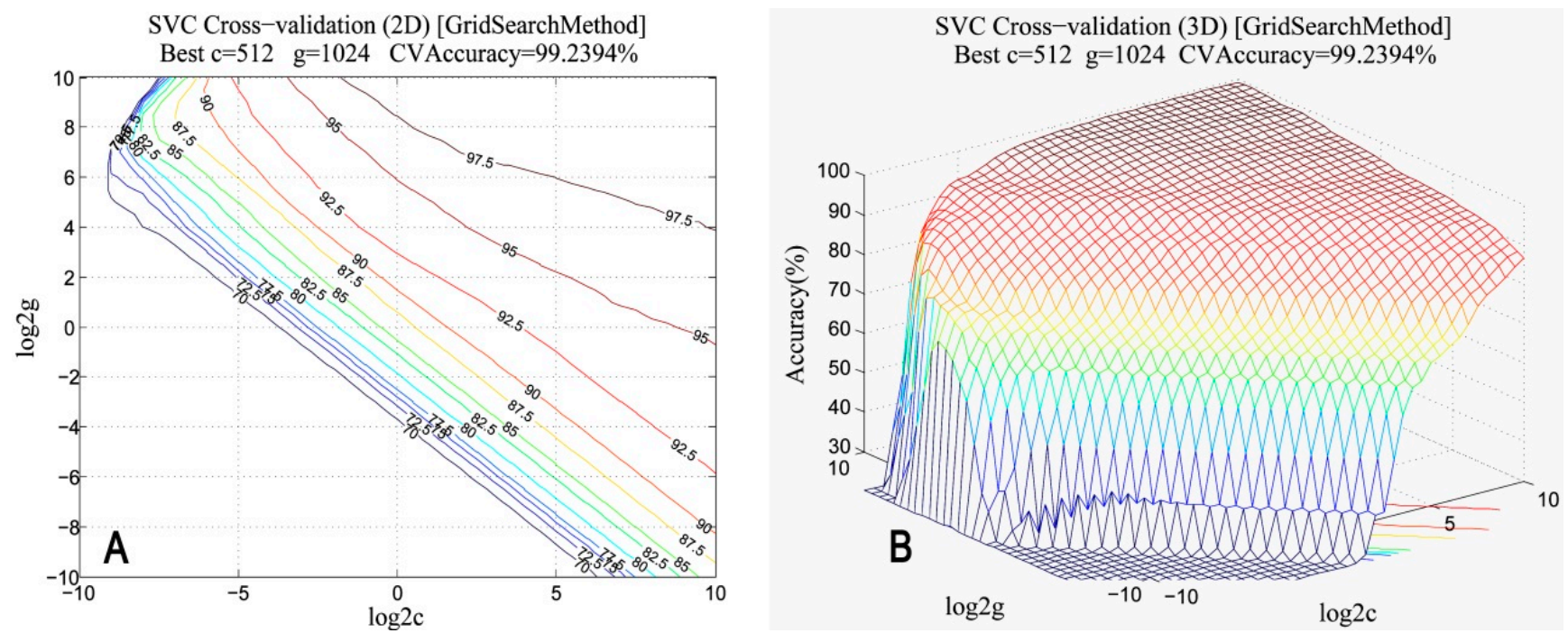

Figure 6. Cont. 

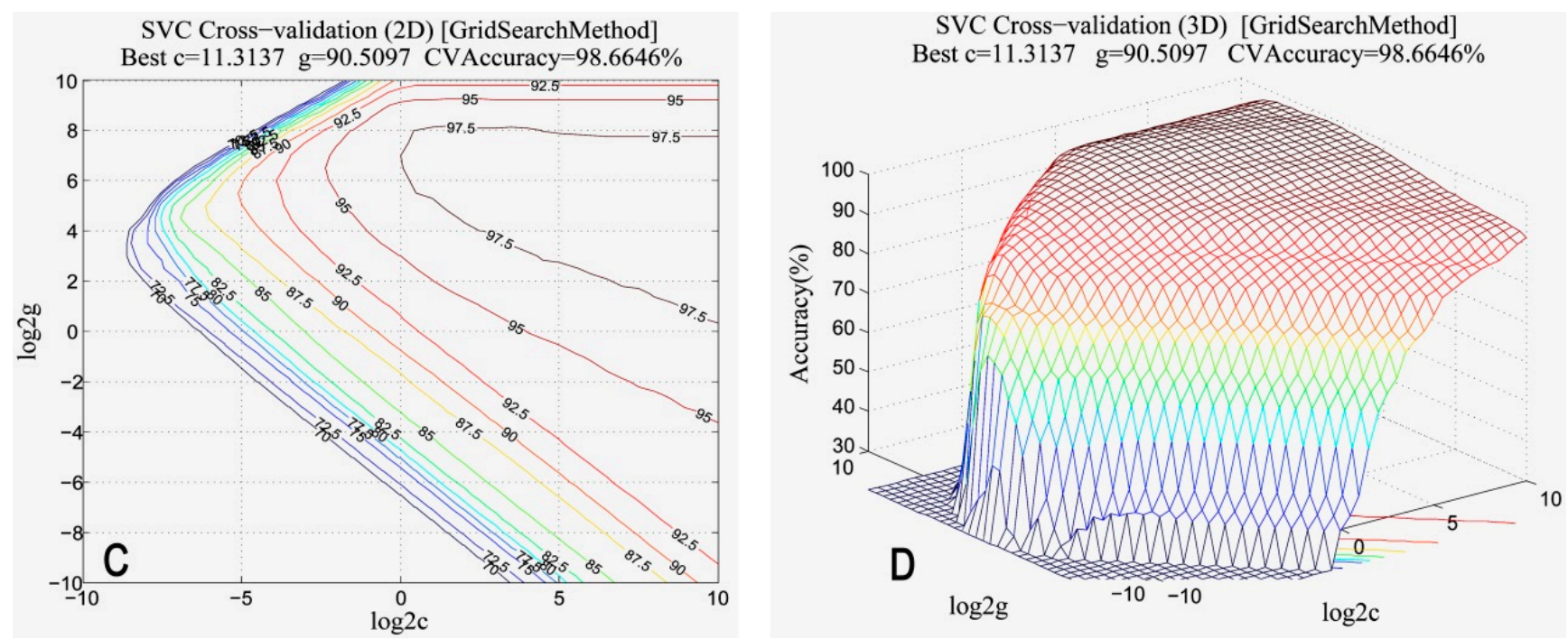

Figure 6. Cross-validation search results for optimal parameters for ETM+ image (A and B) and for ETM+ and PALSAR fusion image (C and D).

As shown in Figure 6, the optimal SVM classification model for both ETM+ and fused images demonstrated a higher CV accuracy. The fused optimal SVM model had slightly lower CV accuracy partly due to the speckle nose increment from PALSAR data and its correspondent addition of complexity for the decision boundaries of SVM that produce the optimal separation of classes.

\subsubsection{SVM Classification}

By utilizing the optimal SVM classification model parameters, we implemented SVM classification for both ETM+ and ETM+ and PALSAR fused images to produce different land cover and severity of soil salinization (i.e., strongly, moderately, and slightly salinized soils). The classification results are shown in Figure 7.

Compared between the ETM+ image and ETM+ and PALSAR fused image, the SVM classification with and without optimal classification parameters for fusion image produced the best results due to the increase of spatial and spectral information after S-PCA fusion. The fused image not only preserved the spectral information from ETM + effectively, but also enhanced the textural and spatial information of both polarimetric $\mathrm{HH}$ and $\mathrm{HV}$ bands of PALSAR image. The classification work was intended to map the environmental context associated with different salinized soil. The focus of the paper was on developing an approach to monitor the salinized soil. Therefore, a detailed description of the classification method was not discussed here since a reader can find them in other publications.

\subsubsection{Classification Accuracy}

The overall accuracy of the SVM classification without and with optimal parameters for ETM+ image was $86.39 \%$ and $87.98 \%$, and Kappa coefficient was 0.83 and 0.85 . The SVM classification of ETM+ and PALSAR fusion images, without and with best parameters, had the highest classification accuracy of $89.82 \%$ and $91.25 \%$, and a Kappa coefficient of 0.88 and 0.89 . The confusion matrices for SVM classification were presented in Table 2 and Table 3. 

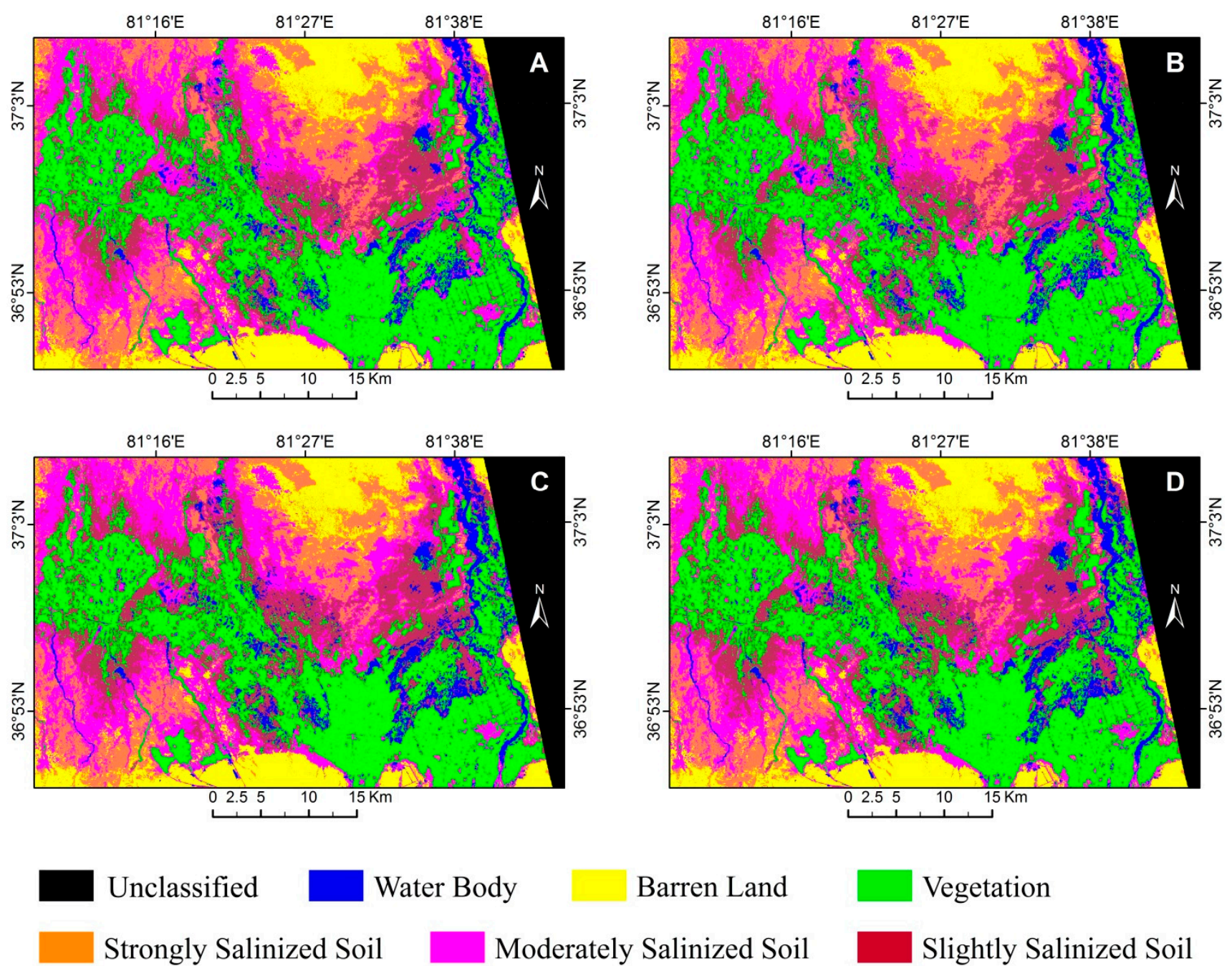

Figure 7. A comparison of different classification results, including the SVM classification of ETM+ image (A); SVM classification of ETM+ image with optimal parameters (B); SVM classification of fused image (C); SVM classification of fused image with optimal parameters (D).

In the confusion matrix of SVM classification with optimal parameters for single ETM+ image (Table 2), yielded the following: (1) The land cover types of water body, barren land, and vegetation agreed well with the field data, especially vegetation was well discriminated from other land cover types; (2) Water body was confused with salinized soil, and barren land was confused with salinized soil and vegetation was confused with water bodies due to the partial similarity in the ETM+ reflectance; (3) Despite the relative higher overall accuracy of the SVM classifier, the different salinized soils were not well separated. Particularly, the slightly salinized soil was confused with moderately salinized soil. Less confusion was observed between different land cover types, particularly between vegetation and water bodies, between strongly and moderately salinized soils, and between moderately and slightly salinized soils with SVM classification with optimal parameters using the fused image of ETM+ and PALSAR (Table 3). Significantly, spectral confusions among different degrees of salinized soils were greatly reduced in the confusion matrix of the fusion image. This was due to the contribution from polarimetric PALSAR image, which improved the classification accuracy; it contributed to the improvement of the spatial resolution and the delineation ability of salinized soil. Moreover, barren land was well 
discriminated despite the similar high reflectance pattern in ETM+ image in strongly salinized soils. Consequently, the classification result of barren land that was achieved from this SVM classification model was adopted for a the decision tree classification as useful input data.

Table 2. The confusion matrix (\%) of SVM classification with optimal parameters using $\mathrm{ETM}+$ image. WB, BL, VG, HS, MS, SS stand for water body, barren land, vegetation, strongly salinized soil, moderately salinized soil and slightly salinized soil. Prod Acc is for a producer's accuracy and User Acc is for a user's accuracy.

\begin{tabular}{ccccccccc}
\hline Class & WB & BL & VG & HS & MS & SS & Prod Acc & User Acc \\
\hline WB & 96.84 & 0 & 0 & 0 & 0.94 & 2.9 & 96.84 & 94.03 \\
BL & 0 & 96.65 & 0 & 1.4 & 0.29 & 0 & 96.65 & 97.52 \\
VG & 0.26 & 0 & 97.33 & 0 & 0 & 0 & 97.33 & 99.85 \\
HS & 0 & 1.7 & 0 & 96.31 & 19.91 & 0.06 & 96.31 & 83.58 \\
MS & 1.27 & 1.65 & 0.03 & 2.16 & 65.74 & 17.71 & 65.74 & 78.67 \\
SS & 1.64 & 0 & 2.63 & 0.13 & 13.12 & 79.33 & 79.33 & 78.57 \\
\hline
\end{tabular}

Overall Accuracy $=87.981 \%$

Kappa Coefficient $=0.8541$

Table 3. The confusion matrix (\%) for SVM classification with optimal parameters using fusion image of ETM+ and PALSAR. WB, BL, VG, HS, MS, SS stand for water body, barren land, vegetation, strongly salinized soil, moderately salinized soil and slightly salinized soil. Prod Acc is for a producer's accuracy and User Acc is for a user's accuracy.

\begin{tabular}{ccccccccc}
\hline Class & WB & BL & VG & HS & MS & SS & Prod Acc & User Acc \\
\hline WB & 99.08 & 0 & 0 & 0 & 1.82 & 4 & 99.08 & 91.24 \\
BL & 0 & 97.64 & 0 & 5.75 & 1.43 & 0 & 97.64 & 90.39 \\
VG & 0.2 & 0 & 98.37 & 0 & 0 & 0.52 & 98.37 & 99.43 \\
HS & 0 & 1.51 & 0.02 & 91.33 & 11.75 & 0 & 91.33 & 88.82 \\
MS & 0.03 & 0.85 & 0.08 & 2.92 & 83.28 & 13.9 & 83.28 & 85.1 \\
SS & 0.69 & 0 & 1.53 & 0 & 1.72 & 81.57 & 81.57 & 94.75 \\
\hline \multicolumn{7}{l}{ Overall Accuracy $=91.25 \%$} \\
\multicolumn{7}{l}{ Kappa Coefficient $=0.8938$}
\end{tabular}

\subsection{Backscattering Feature of Polarimetric PALSAR and Radarsat-2 Data}

Through analyzing the corresponding backscattering values of PALSAR and Radarsat-2 data over the sampled plots, we generated the mean backscattering values of different land cover types as shown in Figure 8. It was observed that the backscattering coefficient of the different land cover types in PALSAR HH polarization image decreased following the order from vegetation, slightly salinized soil, moderately salinized soil, water body, barren land to strongly salinized soil. As for PALSAR HV polarization image, the decreasing order was from vegetation, slightly salinized soil, moderately salinized soil, water body, strongly salinized soil to barren land. The descending order for both Radarsat-2 HH and HV polarized image was from vegetation, slightly salinized soil, water body, moderately salinized soil, barren land to strongly salinized soil. 


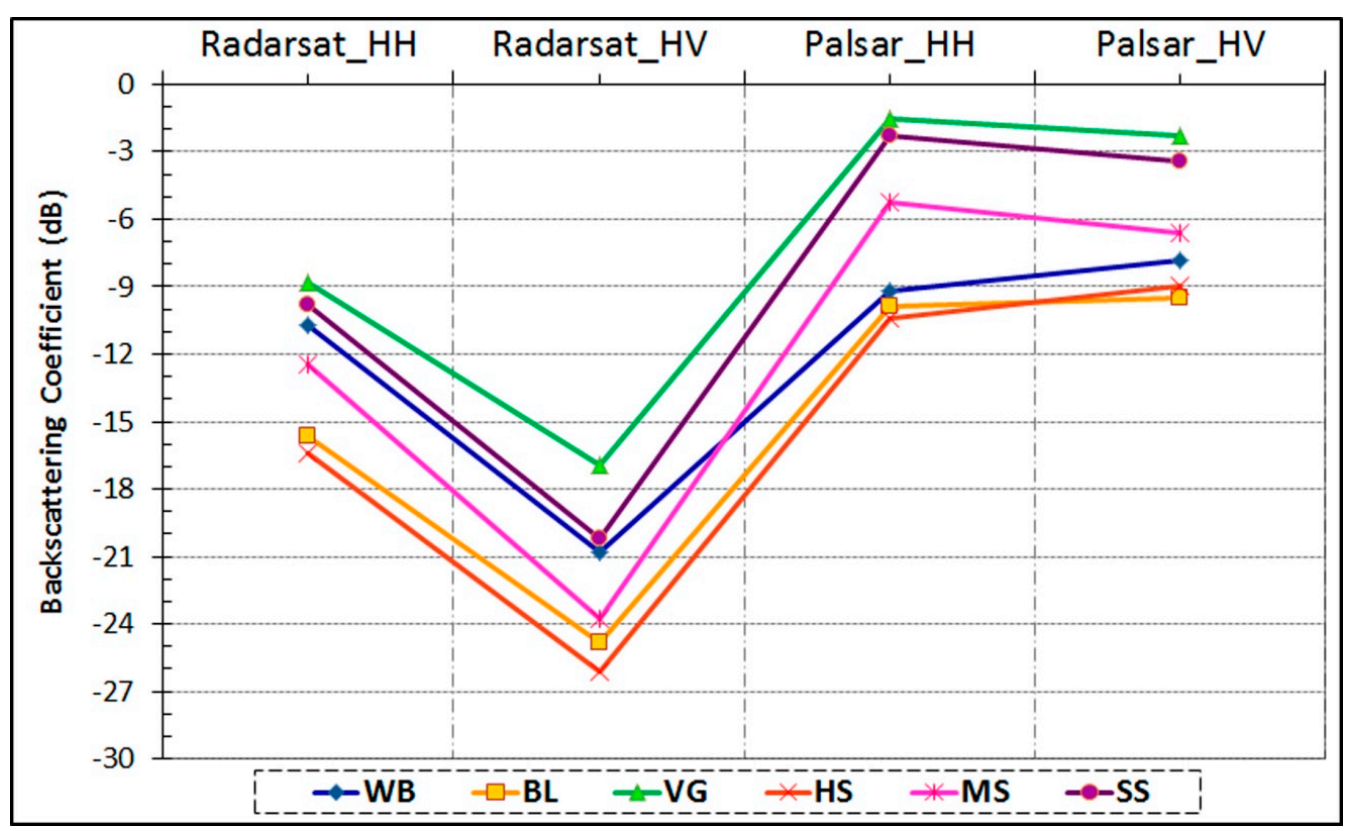

Figure 8. Mean backscattering coefficient of different land cover type in PALSAR L band and Radarsat-2 $\mathrm{C}$ band co-polarization $\mathrm{HH}$ and cross-polarization $\mathrm{HV}$ images.

The overall backscattering coefficients of both PALSAR and Radarsat-2 co-polarization HH images were greater than that of cross-polarization images. However, for all of the PALSAR and Radarsat-2 HH and HV polarization images, the backscattering strength for different salinized soil conforms to the same overall descending trend of slightly salinized soil, moderately salinized soil and strongly salinized soil. The reason for this is that, the slightly salinized soil has the most vegetation coverage, surface roughness and vegetation water content compared with other two soil types. The strongly salinized soil is almost without vegetation coverage and has a very dry top soil surface and saline crust which leads either to specular reflectance or penetration into the soil surface resulting in less backscattered intensity. Moderately salinized soil, which has relatively less vegetation coverage and higher surface roughness, is characterized by medium backscattering intensity in contrast to the other two soil types. For these reasons, there were relatively wider gaps between the different salinized soil types, which were helpful for distinguishing the different salinized soils, especially separating slightly salinized soils from moderately salinized soils.

For further identification of the classification power of PALSAR and Radarsat-2 images among the different types of salinized soils, we generated the backscattering coefficient histograms for the $\mathrm{HH}$ and HV polarized images of both PALSAR and Radarsat- 2 datasets over the field sampling locations (Figure 9). Although there was overlapping of histograms of different salinized soils to some degree, radar data still showed the great potential in discriminating the degree of salinization as evidenced by the measurable distances between the histogram peaks. Particularly, strongly salinized soil was better separated from others in both HH polarized PALSAR and Radarsat-2 images; slightly salinized soil was better discriminated in both HV polarized PALSAR and Radarsat-2 images. Nevertheless, the single image bands could not distinguish the different salinized soils completely; there were certain overlapping areas in all the polarized Radarsat-2 $\mathrm{C}$ band and PALSAR L band images. Therefore in the decision tree scheme, an integrated threshold of backscattering values from both Radarsat-2 C band and PALSAR L band polarimetric images were necessary. 

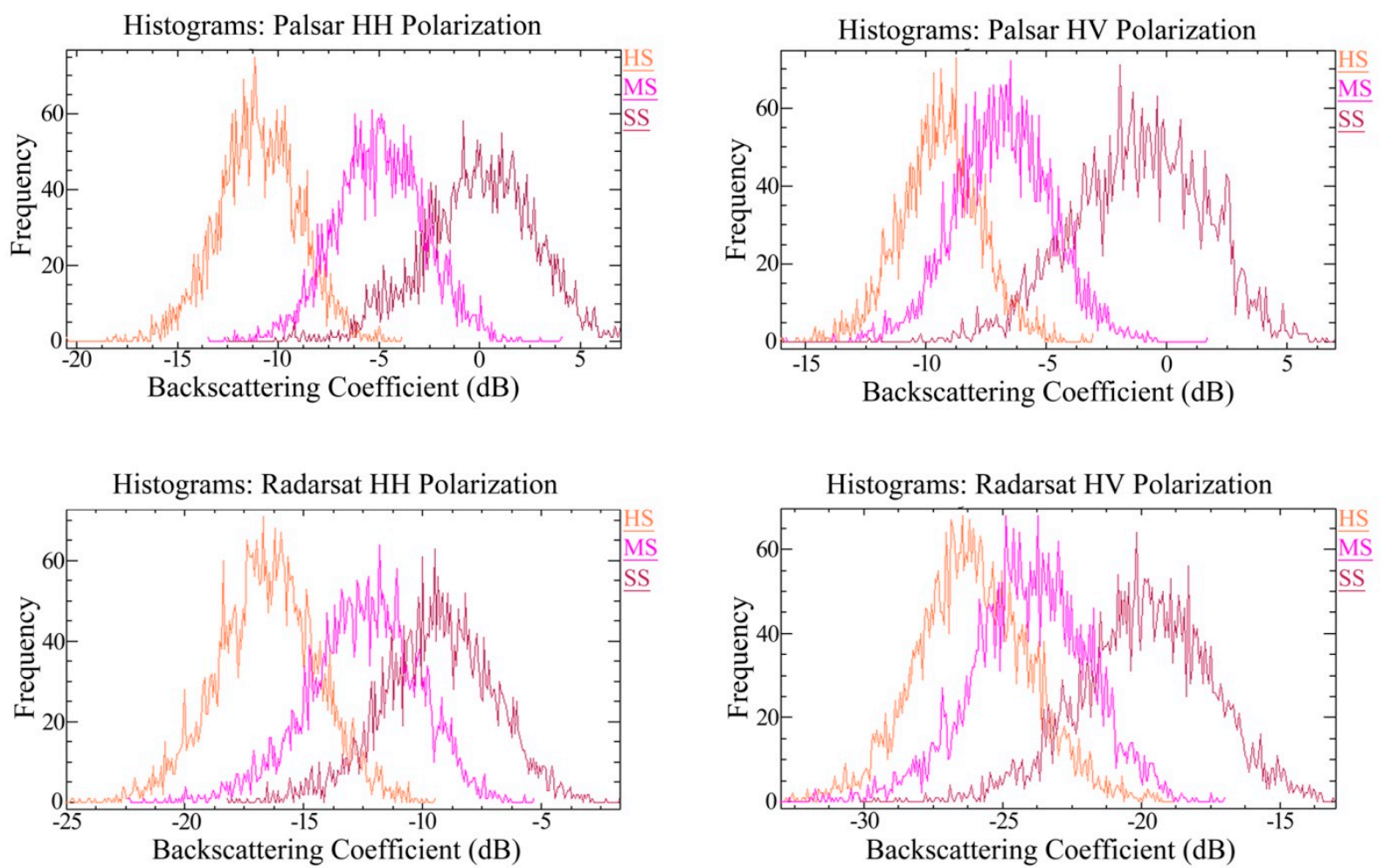

Figure 9. Histogram of different salinized soil types (HS, MS, SS stand for strongly salinized soil, moderately salinized soil and slightly salinized soil respectively) in PALSAR and Radarsat-2 co-polarization HH and cross-polarization HV images.

\subsection{Decision Tree Classification and Accuracy}

Through the analysis of the spectral signature of the main land cover types in the study area, the decision tree classifier for the extraction of different saline soils was established (Figure 10). The optimal threshold values of ETM+ band 4 (near infrared), NDVI, MNDWI, SI, PALSAR HH and HV bands, Radarsat-2 HH and HV bands were determined by the iterative machine learning process. First, the input image pixels were divided into two groups: those with MNDWI values above -0.2 or those with ETM+ band 4 values above 0.12 and less than 0.25 . The water body was extracted successfully in this node. It is worth noting that the near infrared band (band 4) of ETM+ image offered added value to the workflow because a single MNDWI threshold value was not able to extract the swamp effectively due to its confusion with vegetation and slightly salinized soil. Second, the pixels filtered through above criteria were then divided into vegetation and non-vegetation by NDVI threshold of 0.28 . Then, the remaining pixels were divided into barren land and different types of salinized soils according to the result from the SVM classification of ETM+ and PALSAR S-PCA fused image. The SVM classification results were used because the overall classification accuracy of barren land in the fusion image was over $97 \%$ (see Table 3); and, it was hard to discriminate barren land from strongly salinized soil due to their similar backscattering features in radar images. Therefore, in this tree node those pixels equal to barren land in the SVM classification image were determined as barren land. Third, the salinized soils were separated using SAR images. Since PALSAR and Radarsat-2 images have lower backscattering values for strongly salinized soils, we found a comprehensive threshold value for each $\mathrm{HH}$ and HV band of the PALSAR and Radarsat-2 images given in Figure 10. As a result, the strongly salinized soil type was effectively 
extracted. In the final node, we established integrated threshold values for SI, PALSAR and Radarsat-2 data, which allowed separation of slightly and moderately salinized soils. Figure 11 showed that different land cover types and salinized soil types were well discriminated.

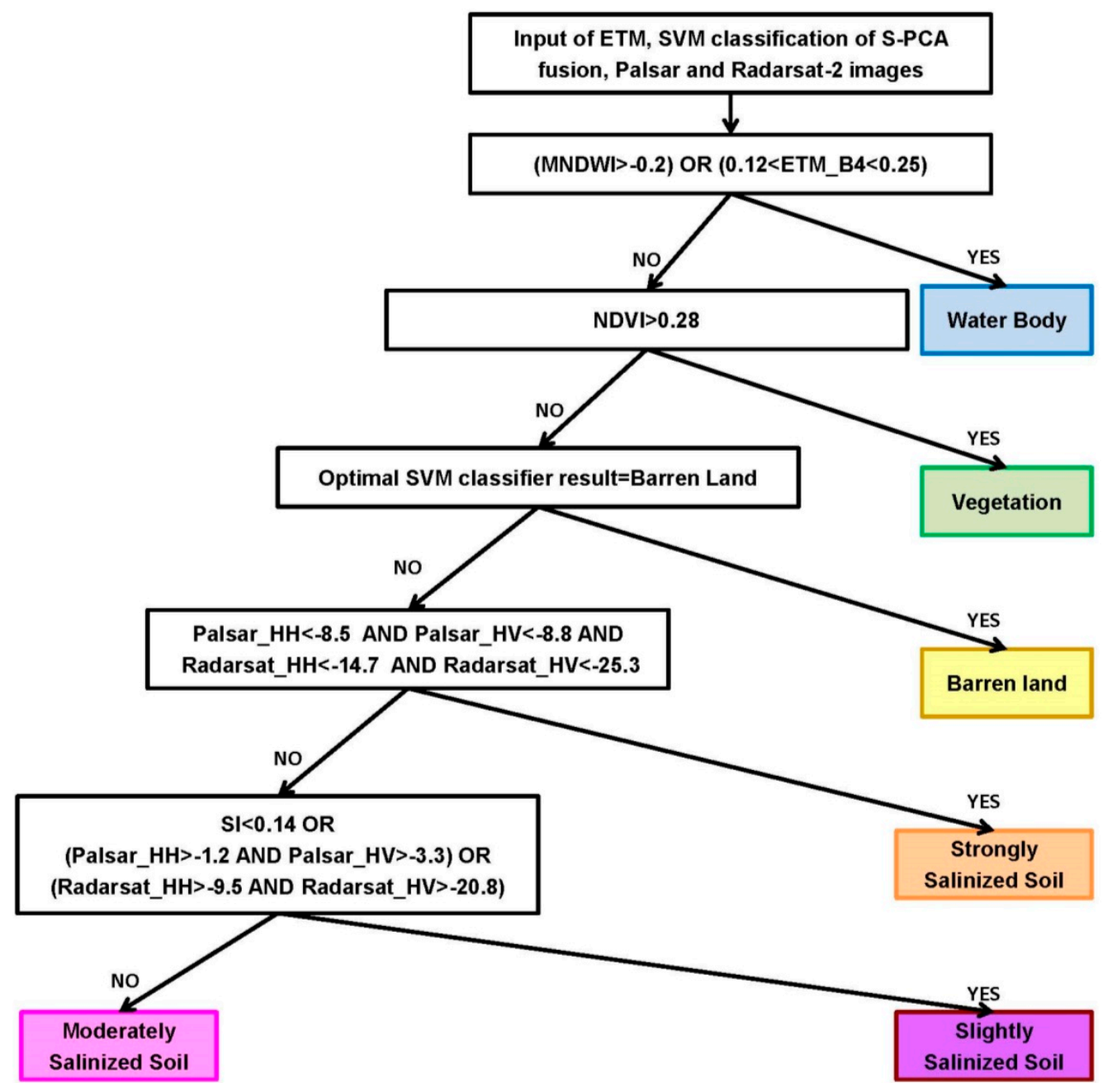

Figure 10. Decision Tree classification model.

Overall accuracy, Kappa coefficient, producer's accuracy and user's accuracy were calculated by using the confusion matrix determined with the validation datasets. The accuracy statistics of the decision tree algorithm is provided in Table 4, and it indicates overall very good agreement (overall accuracy $=93.01 \%$, kappa $=0.92$ ). The performance of the classification algorithms adopted in our research was assessed in terms of errors, not only accuracies. Thus, quantity disagreement and allocation disagreement values were also calculated, which meeting the acceptable accuracy, as shown in Figure 12. The best results were obtained from the DT algorithm, which showed $4.97 \%$ of allocation disagreement and $2.02 \%$ of quantity disagreement. The confusion between moderately salinized soil and slightly salinized soil was significantly reduced in comparison to the SVM classification of the ETM+ and PALSAR fusion image. This was due to our approach. We exploited the merits from both reflectance information of ETM + with different indices for each specific land cover type and from the backscattering features of PALSAR and Radarsat-2 data effectively rather than a simple pixel based fusion between them. The backscattering information from the PALSAR and Radarsat-2 data was well complementary 
for each other in terms of extracting slightly salinized soils from moderately salinized soils. It was evident that the decision tree approach was promising for monitoring salinized soils as well as the degree of salinization in arid and semi-arid areas.

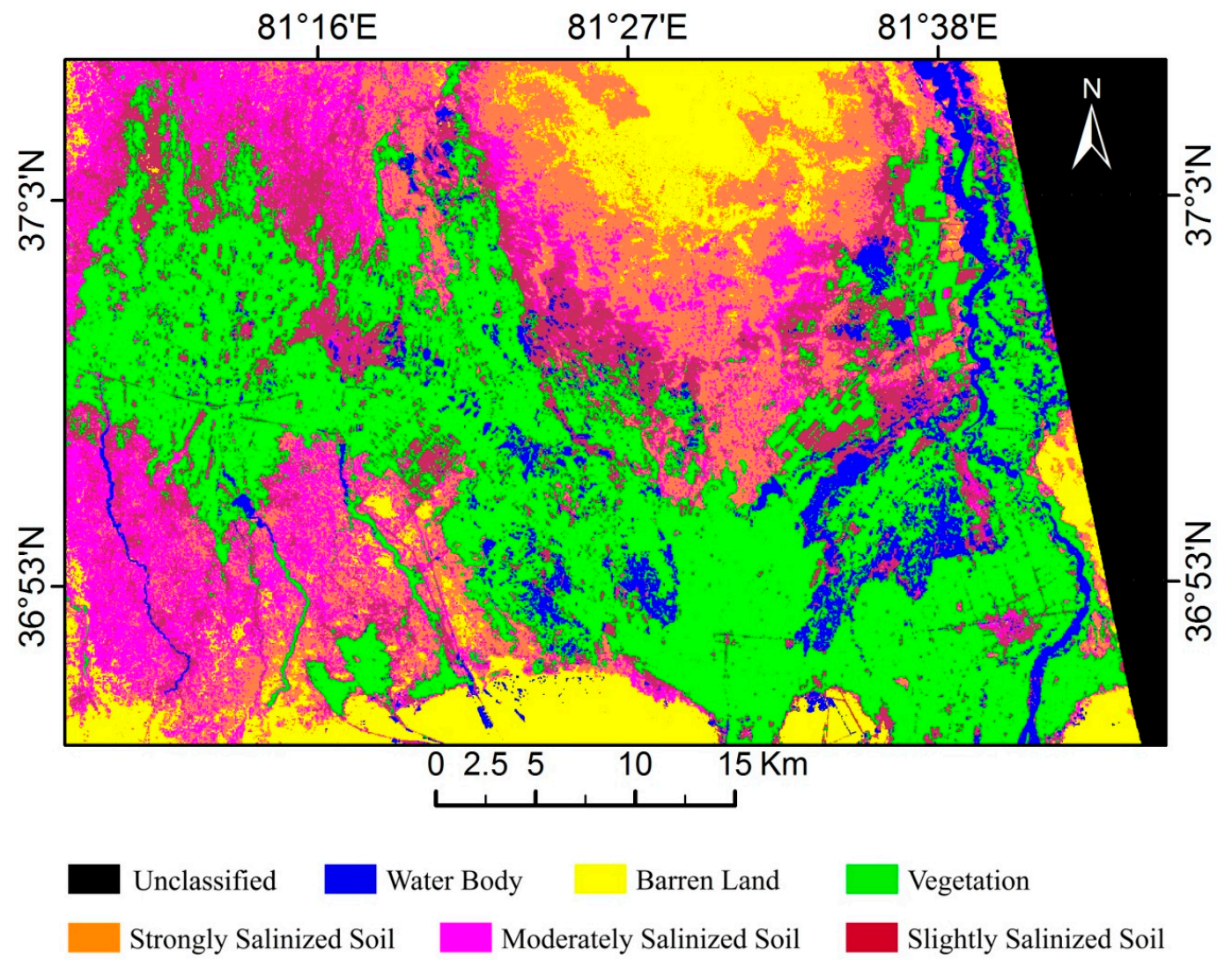

Figure 11. Results of decision tree classification method.

Table 4. The confusion matrix (\%) for Decision Tree classification using the integrated method for ETM+, PALSAR and Radarsat-2 images. WB, BL, VG, HS, MS, SS stand for water body, barren land, vegetation, strongly salinized soil, moderately salinized soil and slightly salinized soil respectively. Prod Acc is for producer's accuracy and User Acc for user's accuracy.

\begin{tabular}{|c|c|c|c|c|c|c|c|c|}
\hline Class & WB & BL & VG & HS & MS & SS & Prod Acc & User Acc. \\
\hline WB & 99.57 & 0 & 0 & 0 & 1.72 & 0.64 & 99.57 & 95.85 \\
\hline $\mathrm{BL}$ & 0 & 97 & 0 & 1.37 & 0.29 & 0 & 97.00 & 97.56 \\
\hline VG & 0.23 & 0 & 97.98 & 0 & 0 & 5.45 & 97.98 & 95.36 \\
\hline HS & 0 & 2.27 & 0.15 & 94.96 & 9.41 & 0.23 & 94.96 & 90.31 \\
\hline MS & 0 & 0.74 & 0.05 & 3.64 & 86.85 & 9.69 & 86.85 & 87.81 \\
\hline SS & 0.2 & 0 & 1.83 & 0.03 & 1.72 & 83.99 & 83.99 & 94.83 \\
\hline \multicolumn{9}{|c|}{ Overall Accuracy $=93.01 \%$} \\
\hline Карра & efficie & $=0.91$ & & & & & & \\
\hline
\end{tabular}




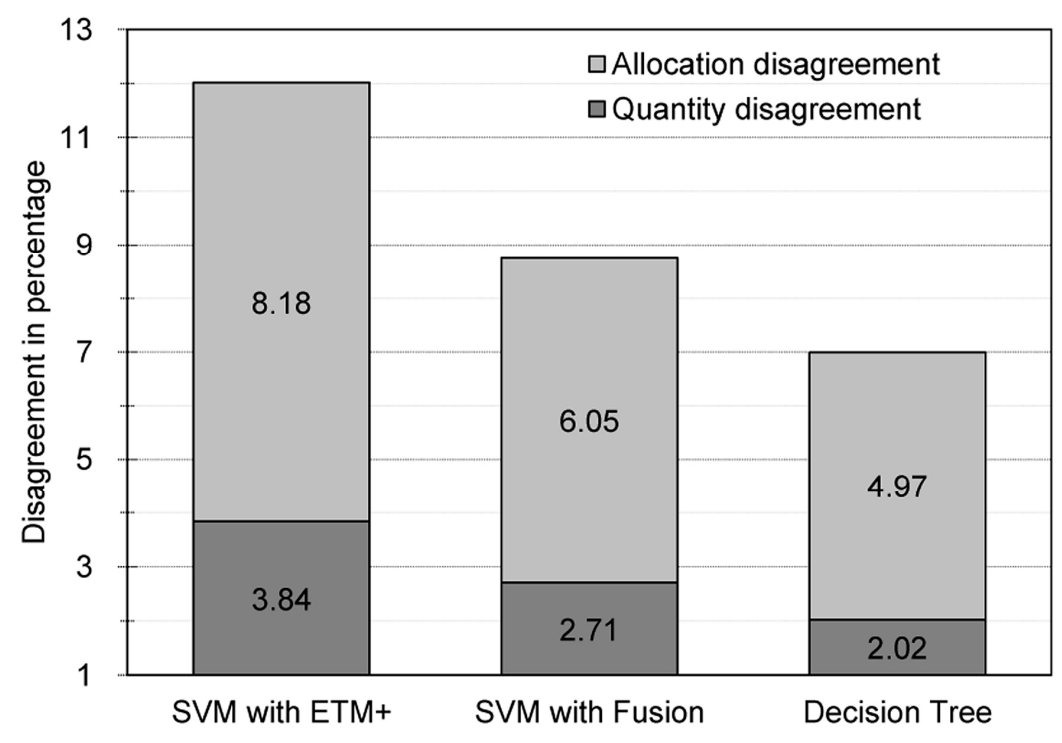

Figure 12. Quantity disagreement and allocation disagreement of different classification algorithms, i.e., the SVM classification of ETM+ image with optimal parameters (SVM with ETM+), SVM classification of fused image with optimal parameters (SVM with Fusion) and Decision Tree.

\section{Discussion}

\subsection{Comparison between SVM and DT Classification Method}

In order to explore the effectiveness of different monitoring methods comparatively, the two methods, i.e., SVM and DT, were assessed using an independent in situ sampling data that include the various types of land cover and salinized soils (see the ground truthing location in Figure 1). The classification results over the validation site are shown in Figure 13. Although water bodies were extracted well overall on SVM results from the ETM+ image, vegetation was mixed with slightly salinized soil due to the closeness of their reflectance value. This was due to the fact that slightly salt affected soil was usually covered with $30 \%$ vegetation which consists of Tamarix chinensis Lour, Phragmites communis, Haloxylon ammodendron, Karelinia caspica (Figure 2). The slightly salinized soils were also confused with moderately salinized soil in many spots; they were distributed over the moderately salinized soil to the west of the validation site, which was not the case in reality according to the ground observations. This was because both of the slightly and moderately salinized soils may have similar vegetation cover, though the coverage percentages are slightly different as the vegetation coverage of the moderately salinized soil is around $5 \% \sim 15 \%$ in average.

The classification results of ETM+ and PALSAR S-PCA fusion images were better than the results of a single ETM+ SVM classification. A better suppression of salt-and-pepper like noise was achieved by the SVM classification of the fusion image. Water bodies were well delineated; however, vegetation is still confused with slightly salinized soil. Most importantly, the separation of slightly and moderately salinized soil was noticeably improved, and the moderately salinized soil to the west was well discriminated from the strongly salinized soil. This was partly due to the contribution of high spatial and distinct polarimetric backscattering characteristics from SAR data, the S-PCA fused image was 
improved both in spectral and spatial quality, and it enhanced the distinguishing ability of different salinized soil.

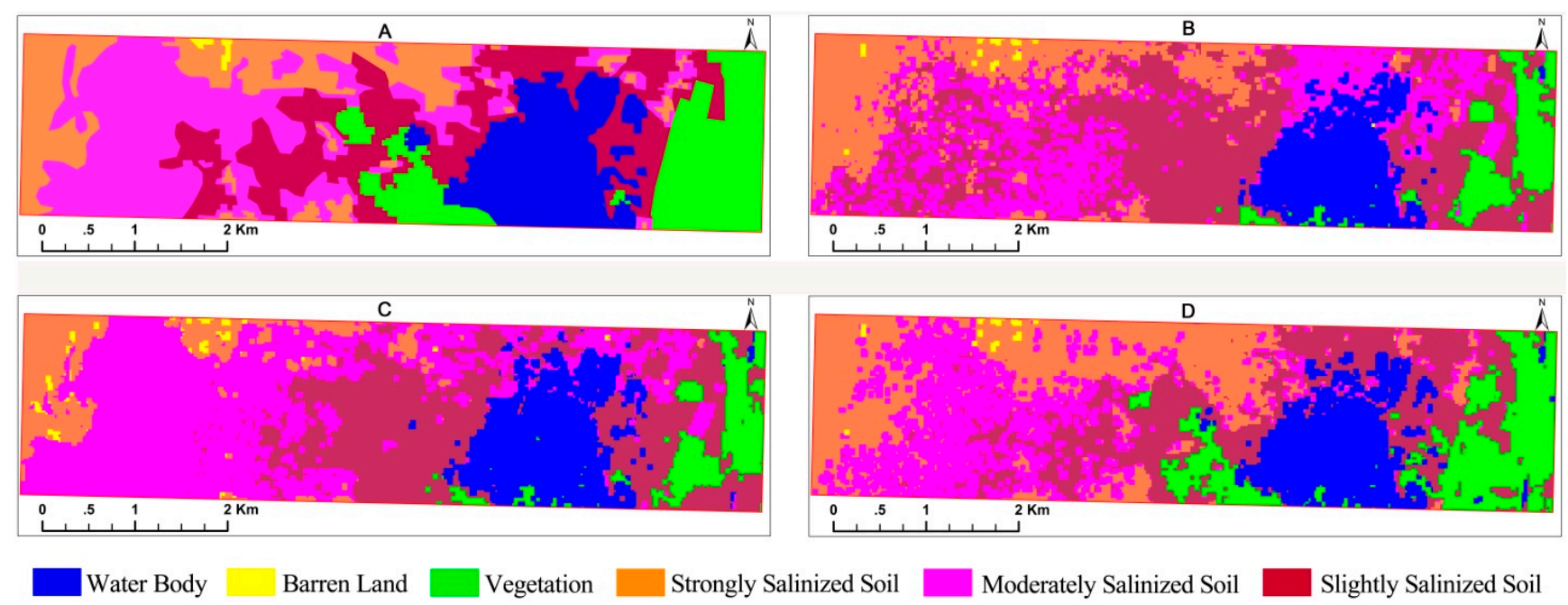

Figure 13. The ground truthing (A) and corresponding classification maps of SVM for ETM+ (B); SVM for fused image of ETM+ and PALSAR (C) and DT classification (D).

The best results were achieved from the DT classification. Water bodies were extracted more precisely due to the integrated threshold values of MNDWI and ETM+ band 4. Swamp was also well delineated from slightly salinized soil and vegetation. Most importantly, strongly, moderately, slightly salinized soils were well discriminated in this image in comparison to the other approaches. The overall distribution of salinized soils was well reflected from the DT classification. From east to west, the land cover types shift from vegetation to slightly salinized soil, moderately salinized soil and strongly salinized soil. The results further confirm that PALSAR and Radarsat-2 polarimetric data were able to separate strongly salinized soil from the other two types of salinized soils effectively due to its low backscattering intensity. We conclude that the integrated method of passive optical and active microwave data is the most promising approach in monitoring various degrees of soil salinization.

\subsection{Area of Salinized Soil}

As shown in Figure 11, the strongly salinized soil is distributed mainly on the lower reaches of the Keriya River basin, and between the two long "legs of the oases" located in the north of the study area, which transcend to desert. Moderately salinized soil is distributed in the outskirt of the Keriya River Oases within the ecotone between Keriya Oases and the Taklimakan desert. Slightly salinized soil is distributed to the transient area between vegetation and moderately salinized soil.

Strongly salinized soil alone occupies about $10.71 \%$ of the study area (20613.84 ha), moderately salinized soil accounts for around 19.86\% (38247.56 ha) and slightly for 10.86\% (20902.40 ha) (Table 5). In addition, there are about 79763.8 ha of total salinized soil within the study area (41.43\%), indicating that soil salinity has already become one of the major threats to the local agriculture and human activities. These outcomes strongly highlight the critical need for proactive management and protection of the Keriya River basin from soil salinization since the consequences of not doing so are severe, not just limited to oases acreage lost also to its negative impact on the agricultural productivity 
that is directly linked to the income of the local population. Future efforts and reasonable management strategies should focus on maintaining and improving the Keriya River basin's soil resources to limit further disturbance from salinized soils and land use changes which in turn lead to secondary soil salinization.

Table 5. Land-cover class statistics of the study area.

\begin{tabular}{ccccccc}
\hline & Water Body & Vegetation & $\begin{array}{c}\text { Barren } \\
\text { Land }\end{array}$ & $\begin{array}{c}\text { Strongly } \\
\text { Salinized Soil }\end{array}$ & $\begin{array}{c}\text { Moderately } \\
\text { Salinized Soil }\end{array}$ & $\begin{array}{c}\text { Slightly } \\
\text { Salinized Soil }\end{array}$ \\
\hline $\begin{array}{c}\text { Class area (\%) } \\
\text { Class area (hectare) }\end{array}$ & 6.932 & 33.817 & 17.826 & 10.706 & 19.864 & 10.856 \\
\hline
\end{tabular}

\subsection{Uncertainty Analysis}

When the fraction of vegetation is less than $15 \%$, surface spectral reflectance may look more similar to bare land. Land surface reflectance may appear as the mix of vegetation and bare land for vegetation fraction varying between $15 \%$ and $70 \%$. A pixel can be considered as a "pure" vegetation pixel when the vegetation fraction is over 70\% [54]. Minimizing the interference of vegetation is critical for accurate extraction of soil salinity information from optical imagery. We found that salt tolerant vegetation such as Tamarix chinensis Lour, Phragmites communis, Halocnemum strobilaceum, Halostachys caspica, Alhagi pseudalhagi can grow in various salinized soils, especially in slightly and moderately salinized soils. These salt-tolerant plants can contaminate the spectral reflectance of salinized soil in optical images, which result in spectral mixture [6].

Radar images may suffer from speckle noise, which are light and dark pixels produced by a constructive or destructive interference from radar waves. Speckle is granular "noise" that inherently exists in and degrades the quality of SAR images. Speckle noise in our study was reduced through multi-looking and Refined Lee filtering. However, those filtering methods cannot completely remove the speckle noise in radar images. The fusion image based classification accuracy may have been hampered by the remaining speckle noise.

Additionally, the backscattering power observed by radar imagery is affected by complex factors such as soil moisture, surface roughness, vegetation elevation, water content of vegetation, inclination of land surface and the dielectric properties of the soil. For this reason, the backscatter intensity from salt affected soils may include contributions from other influencing factors mentioned above. Therefore, it is a challenge to detect and map soil salinization by using radar image alone. And these complexities may affect the monitoring accuracy of salinized soil in our integrated approach from both optical and radar data. In our future study, we will incorporate soil moisture and soil roughness for better interpretation of soil salinity distribution.

\section{Conclusions}

In this paper, we presented a passive reflective and active microwave remote sensing data fusion algorithm to monitor soil salinity. Our major conclusions include the following: (1) The support vector machine (SVM) classification with the optimal parameters obtained from cross-validation methods was identified as the best model for a pixel based classification approach. The overall classification accuracy 
of ETM+ data with the SVM without and with optimal parameters were $86.39 \%$ and $87.98 \%$, and Kappa coefficients were 0.83 and 0.85 , respectively. The classification result of ETM+ and PALSAR S-PCA fused images was better than the single ETM+ image classification. The overall SVM classification accuracies of the fusion image without and with optimal parameters were $89.82 \%$ and $91.25 \%$, respectively. The Kappa coefficients of the fusion image without and with optimal parameters were 0.88 and 0.89 respectively; (2) The polarimetric PALSAR and Radarsat-2 backscattering coefficients showed that there were significant differences between the different degrees of salt-affected soil types, which were helpful for discriminating slightly salinized soils from moderately salinized soils. None of the single HH or HV images alone was able to distinguish the different salinized soils. An integrated threshold of backscattering values from both PALSAR and Radarsat-2 polarimetric images was found to be important in separating moderately salinized and heavily salinized soils as well; (3) The decision tree (DT) approach developed by integration of ETM+, PALSAR and Radarsat-2 data yielded the most accurate results with overall accuracy of $93.01 \%$ and Kappa coefficient of 0.92 , and with lowest disagreement of allocation and quantity. The DT classifier exploited both the potential of optical reflectance and microwave backscattering features. It was particularly efficient in separating slightly salinized soil from moderately salinized soil; (4) Strongly salinized soil alone occupied about $10.71 \%$ (20,613.84 ha), and moderately salinized soils accounted for 19.86\% (38,247.56 ha) and slightly salinized soils for $10.86 \%(20,902.40 \mathrm{ha})$ of the study area. The total salinized soil within the study area was $41.43 \%$ (79,763.8 ha), indicating that soil salinity had already become one of the major threats to the agricultural productivity and sustainable development of local eco-environment.

\section{Acknowledgments}

This work was jointly supported by multiple grants from the National Natural Science Foundation of China (No. U1138303), Joint Funds of the International S\&T Cooperation Program of China (ISTCP, 2010DFA92720-12), Excellent Ph.D. Students Innovation Foundation of Xinjiang University (No. XJUBSCX-2013012) and the Open Project of Ministry of Education Key Laboratory of Oasis Ecology, Xinjiang University (No. XJDX0201-2013-06). Finally, we also extend our gratitude to the anonymous reviewers of this manuscript for their helpful comments and suggestions provided during the preparation.

\section{Author Contributions}

Ilyas Nurmemet conceived the idea for this paper, and was responsible for the research design and analysis. The second author Abduwasit Ghulam provided theoretical and technical guidance, and offered invaluable suggestions for paper revision. Tashpolat Tiyip mentored and supervised the work, and Jian-li Ding provided assistance to coordinate the research projects. Racha Elkadiri and Matthew Maimaitiyiming offered valuable suggestions and helped in revision of the manuscript. Mamat Sawut and Fei Zhang served as scientific advisors. Abdulla Abliz, Abdugheni Abliz and Qian Sun conducted the field investigations and collected the data. The data were processed, analyzed and final paper was written by Ilyas Nurmemet and sent to all authors for comments and edits. 


\section{Conflicts of Interest}

The authors declare no conflict of interest.

\section{References}

1. Farifteh, J.; Farshad, A.; George, R.J. Assessing salt-affected soils using remote sensing, solute modelling, and geophysics. Geoderma 2006, 130, 191-206.

2. Metternicht, G.I.; Zinck, J.A. Remote sensing of soil salinity: Potentials and constraints. Remote Sens. Environ. 2003, 85, 1-20.

3. Wu, J.; Li, P.; Qian, H.; Fang, Y. Assessment of soil salinization based on a low-cost method and its influencing factors in a semi-arid agricultural area, northwest China. Environ. Earth Sci. 2014, $71,3465-3475$.

4. Li, Y.; Zhao, K.; Ding, Y.; Ren, J. An empirical method for soil salinity and moisture inversion in West of Jilin. In Proceedings of the 2013 the International Conference on Remote Sensing, Environment and Transportation Engineering (RSETE 2013), Nanjing, China, 26-28 July 2013; pp. 19-21.

5. Wang, H.; Jia, G. Satellite-based monitoring of decadal soil salinization and climate effects in a semi-arid region of China. Adv. Atmos. Sci. 2012, 29, 1089-1099.

6. Metternicht, G.I. Analysing the relationship between ground-based reflectance and environmental indicators of salinity processes in the Cochabamba valleys (Bolivia). Int. J. Ecol. Environ. Sci. 1998, 24, 359-370.

7. Metternicht, G.; Zinck, J.A. Spatial discrimination of salt- and sodium-affected soil surfaces. Int. J. Remote Sens. 1997, 18, 2571-2586.

8. Nawar, S.; Buddenbaum, H.; Hill, J. Digital mapping of soil properties using multivariate statistical analysis and ASTER data in an arid region. Remote Sens. 2015, 7, 1181-1205.

9. Allbed, A.; Kumar, L.; Sinha, P. Mapping and modelling spatial variation in soil salinity in the Al Hassa Oasis based on remote sensing indicators and regression techniques. Remote Sens. 2014, 6, $1137-1157$.

10. Eldeiry, A.A.; Garcia, L.A. Comparison of ordinary kriging, regression kriging, and cokriging techniques to estimate soil salinity using Landsat images. J. Irrig. Drain. Eng. 2010, 136, 355-364.

11. Aldabaa, A.A.A.; Weindorf, D.C.; Chakraborty, S.; Sharma, A.; Li, B. Combination of proximal and remote sensing methods for rapid soil salinity quantification. Geoderma 2015, 239, 34-46.

12. Masoud, A.A. Predicting salt abundance in slightly saline soils from Landsat ETM+ imagery using spectral mixture analysis and soil spectrometry. Geoderma 2014, 217, 45-56.

13. Nawar, S.; Buddenbaum, H.; Hill, J.; Kozak, J. Modeling and mapping of soil salinity with reflectance spectroscopy and Landsat data using two quantitative methods (PLSR and MARS). Remote Sens. 2014, 6, 10813-10834.

14. Sidike, A.; Zhao, S.; Wen, Y. Estimating soil salinity in Pingluo County of China using QuickBird data and soil reflectance spectra. Int. J. Appl. Earth Obs. Geoinf. 2014, 26, 156-175.

15. Fan, X.; Liu, Y.; Tao, J.; Weng, Y. Soil salinity retrieval from advanced multi-spectral sensor with partial least square regression. Remote Sens. 2015, 7, 488-511. 
16. Jin, P.; Li, P.; Wang, Q.; Pu, Z. Developing and applying novel spectral feature parameters for classifying soil salt types in arid land. Ecol. Indic. 2015, 54, 116-123.

17. Sreenivas, K.; Venkataratnam, L.; Rao, P.V.N. Dielectric properties of salt-affected soils. Int. J. Remote Sens. 1995, 16, 641-649.

18. Gharechelou, S.; Tateishi, R.; Sumantyo, J. Interrelationship analysis of L-band backscattering intensity and soil dielectric constant for soil moisture retrieval using PALSAR data. Adv. Remote Sens. 2015, 4, 15-24.

19. Rhoades, J.D. Electrical Conductivity Methods for Measuring and Mapping Soil Salinity; Academic Press: Waltham, MA, USA, 1993.

20. Shao, Y.; Hu, Q.; Guo, H.; Lu, Y.; Dong, Q.; Han, C. Effect of dielectric properties of moist salinized soils on backscattering coefficients extracted from RADARSAT image. IEEE Trans. Geosci. Remote Sens. 2003, 41, 1879-1888.

21. Ghulam, A.; Porton, I.; Freeman, K. Detecting subcanopy invasive plant species in tropical rainforest by integrating optical and microwave (InSAR/PolInSAR) remote sensing data, and a decision tree algorithm. ISPRS J. Photogramm. Remote Sens. 2014, 88, 174-192.

22. Ghulam, A. Monitoring tropical forest degradation in Betampona Nature Reserve, Madagascar, using multisource remote sensing data fusion. IEEE J. Sel. Top. Appl. Earth Obs. Remote Sens. 2014, 7, 1-12.

23. Mu, Q.; Zi-an, Z.; Hong, M. Survey on the Arable Land Resource of Xinjiang Based on Remote Sensing; Science and Technology Publishing House of Xinjiang: Urumqi, China, 2005.

24. Tashpolat, T.; Fei, Z.; Jianli, D. Study on the spatial information on salinized soil of typical oases in arid areas. Arid L. Geogr. 2007, 4, 544-551.

25. Yang, $\mathrm{X}$. The oases along the Keriya River in the Taklamakan Desert, China, and their evolution since the end of the last glaciation. Environ. Geol. 2001, 41, 314-320.

26. Ling, H.; Xu, H.; Zhang, Q. Nonlinear analysis of runoff change and climate factors in the headstream of Keriya River, Xinjiang. Geogr. Res. 2012, 31, 792-802. (in Chinese)

27. Yuquan, L. The climatic characteristics and its changing tendency in the Taklimakan desert. J. Desert Res. 1990, 2, 9-19.

28. Scaramuzza, P.; Micijevic, E.; Chander, G. SLC Gap-Filled Products Phase One Methodology. Available online: https://landsat.usgs.gov/documents/SLC_Gap_Fill_Methodology.pdf (accessed on 13 April 2015).

29. Lopes, A.; Touzi, R.; Nezry, E. Adaptive speckle filters and scene heterogeneity. IEEE Trans. Geosci. Remote Sens. 1990, 28, 992-1000.

30. Holecz, F.; Meier, E.; Piesbergen, J.; Nisch, D.; Moreira, J. Rigorous derivation of backscattering coefficient. IEEE Geosc. Remote Sens. Soc. Newsletter. 1994, 92, 6-14.

31. Sarmap, S.A. Synthetic Aperture Radar and SARscape: SAR Guidebook; Sarmap SA: Purasca, Switzerland, 2009.

32. Ulaby, F.T.; Dobson, M.C. Handbook of Radar Scattering Statistics for Terrain; Artech House: Norwood, MA, USA, 1989.

33. Chander, G.; Markham, B.L.; Helder, D.L. Summary of current radiometric calibration coefficients for Landsat MSS, TM, ETM+, and EO-1 ALI sensors. Remote Sens. Environ. 2009, 113, 893-903. 
34. Vermote, E.F.; Tanré, D.; Deuzé, J.L.; Herman, M.; Morcrette, J.J. Second simulation of the satellite signal in the solar spectrum, 6S: An overview. IEEE Trans. Geosci. Remote Sens. 1997, 35, 675-686.

35. Xu, H. A Study on information extraction of water body with the Modified Normalized Difference Water Index (MNDWI). J. Remote Sens. 2005, 9, 589-595.

36. Khan, N.M.; Rastoskuev, V.V.; Sato, Y.; Shiozawa, S. Assessment of hydrosaline land degradation by using a simple approach of remote sensing indicators. Agri. Water Manag. 2005, 77, 96-109.

37. Khan, N.M.; Sato, Y. Monitoring hydro-salinity status and its impact in irrigated semi-arid areas using IRS-1B LISS-II data. Asian J. Geoinform 2001, 1, 63-73.

38. Wang, F.; Chen, X.; Luo, G.; Ding, J.; Chen, X. Detecting soil salinity with arid fraction integrated index and salinity index in feature space using Landsat TM imagery. J. Arid Land 2013, 5, 340-353.

39. Douaoui, A.E.K.; Nicolas, H.; Walter, C. Detecting salinity hazards within a semiarid context by means of combining soil and remote-sensing data. Geoderma 2006, 134, 217-230.

40. Khan, N.M.; Sato, Y. Environmental land degradation assessment in semi-arid Indus basin area using IRS-1B LISS-II data. In Proceedings of the IEEE 2001 International Geoscience and Remote Sensing Symposium, Sydney, Ausralia, 9-13 July 2001; Volume 5, pp. 2100-2102.

41. Campbell, N.A.; Wu, X. Gradient cross correlation for sub-pixel matching. In Proceedings of the Congress of the International Society for Photogrammetry and Remote Sensing, Beijing, China, 7 July 2008; pp. 1065-1070.

42. Zhou, J.; Civco, D.L.; Silander, J.A. A wavelet transform method to merge Landsat TM and SPOT panchromatic data. Int. J. Remote Sens. 1998, 19, 743-757.

43. Vapnik, V.N. The Nature of Statistical Learning Theory; Springer-Verlag: Berlin, Germany 1995.

44. Keerthi, S.S.; Lin, C.-J. Asymptotic behaviors of support vector machines with Gaussian kernel. Neural Comput. 2003, 15, 1667-1689.

45. Chang, C.-C.; Lin, C.-J. LIBSVM: A library for support vector machines. ACM Trans. Intell. Syst. Technol. 2011, 2, 1-27.

46. Andrew, M.; Ustin, S.L. The role of environmental context in mapping invasive plants with hyperspectral image data. Remote Sens. Environ. 2008, 112, 4301-4317.

47. Friedl, M.A.; Brodley, C.E. Decision tree classification of land cover from remotely sensed data. Remote Sens. Environ. 1997, 61, 399-409.

48. Hansen, M.; Dubayah, R.; Defries, R. Classification trees: An alternative to traditional land cover classifiers. Int. J. Remote Sens. 1996, 17, 1075-1081.

49. Elnaggar, A.A.; Noller, J.S. Application of remote-sensing data and decision-tree analysis to mapping salt-affected soils over large areas. Remote Sens. 2009, 2, 151-165.

50. Pontius, R.G.; Millones, M. Death to Kappa: Birth of quantity disagreement and allocation disagreement for accuracy assessment. Int. J. Remote Sens. 2011, 32, 4407-4429.

51. Congalton, R.G.; Green, K. Assessing the Accuracy of Remotely Sensed Data: Principles and Practices; CRC press: Boca Raton, FL, USA, 2010.

52. Congalton, R.G. A review of assessing the accuracy of classifications of remotely sensed data. Remote Sens. Environ. 1991, 37, 35-46. 
53. Badreldin, N.; Goossens, R. Monitoring land use/land cover change using multi-temporal Landsat satellite images in an arid environment: A case study of El-Arish, Egypt. Arab. J. Geosci. 2014, 7, 1671-1681.

54. Jia, H.F.; Liu, X. Principle and Application of Environmental Remote Sensing; Tsinghua University Press: Beijing, China, 2006.

(C) 2015 by the authors; licensee MDPI, Basel, Switzerland. This article is an open access article distributed under the terms and conditions of the Creative Commons Attribution license (http://creativecommons.org/licenses/by/4.0/). 